\title{
$\mathrm{PH} 944_{\text {ivesitiaacion }}$
}

\section{Dinosaurios de la Península Ibérica}

\author{
Luis Alcalá, Alberto Cobos, Rafael Royo-Torres | Fundación Conjunto Paleontológico \\ de Teruel-Dinópolis/Museo Aragonés de Paleontología
}

URL de la contribución <www.iaph.es/revistaph/index.php/revistaph/article/view/4145>

\section{RESUMEN}

Los documentos históricos más antiguos relacionados con los dinosaurios de la Península Ibérica provienen de una leyenda portuguesa de origen religioso del siglo XIII: en una ermita conmemorativa situada al sur de Lisboa se encuentra un mural cerámico del siglo XVIII que incluye la representación de huellas de dinosaurios. No obstante, los primeros estudios de fósiles de dinosaurios de Portugal y de España se publicaron a finales del siglo XIX. Desde entonces se ha demostrado que la Península Ibérica contiene un registro muy destacado de dinosaurios que se extiende desde el Jurásico Medio hasta el Cretácico terminal; la gran diversidad de tipos que contiene, su abundancia y el prolongado intervalo temporal representado -100 millones de años- convierten a la Península Ibérica en una de las áreas de mayor interés para el estudio de los dinosaurios y de su evolución. Así, se han descrito 40 nuevas especies y se ha presentado una treintena de tesis doctorales sobre fósiles de dinosaurios ibéricos en universidades de España y Portugal. Asimismo se han excavado, habilitado y protegido legalmente numerosos yacimientos (especialmente de huellas) y también se han impulsado socioeconómicamente algunas zonas carentes de otros recursos mediante la creación de centros paleontológicos de diversa envergadura. Todo ello permite aventurar un futuro todavía más prometedor para el incremento de la repercusión internacional de la Península Ibérica en el ámbito científico de los dinosaurios, así como en el de la gestión del patrimonio paleontológico con objeto de promover su conservación y utilización como recurso educativo y geoturístico.

\section{Palabras clave}

Dinosaurios | Conservación | Difusión | Fósiles | Geoturismo | Investigación | Península Ibérica | 


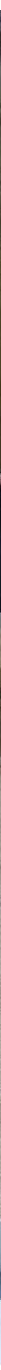

La reconstrucción del carcarodontosaurio Concavenator en acción de perseguir a un iguanodontio en el Museo de Paleontología de Castilla-La Mancha (Cuenca) | foto Luis Alcalá, autor de todas las imágenes que ilustran este artículo foto mientras no se indique lo contrario 


\section{LOS INICIOS}

Los fósiles siempre se han encontrado en nuestro entorno y han formado parte de folclores y mitos cotidianos. En este sentido, sabemos que los humanos ya se relacionaban con ellos desde hace cerca de 100.000 años pues utilizaron, por ejemplo, fósiles de erizos de mar como raspadores. El ser humano convivió con los restos de seres vivos del pasado, entre ellos los dinosaurios, sin haber comprendido todavía su verdadera procedencia, y suponemos que interpretarían de una forma mística-religiosa o con la racionalidad de la época algo que para ellos era desconocido. La atracción que le despertaban tales curiosidades, sin saber entonces en realidad qué eran ni a qué seres habían pertenecido, se ha mantenido hasta nuestros días en los que ya manejamos respuestas acerca de su significado.

Para encontrar los vestigios históricos más antiguos de fósiles de dinosaurios en la Península Ibérica tenemos que dirigirnos a Portugal. Nada menos que del siglo XIII data la leyenda de Nossa Senhora da Pedra da Mua, escenificada en la bahía de Lagosteiros al sur de Lisboa. Dicha leyenda relata que la Virgen María, montada en una mula ("mua") con el Niño Jesús, subió desde el mar a través de los acantilados existentes al norte de cabo Espichel, concretamente remontando un estrato casi vertical. La leyenda se fundamentaba en la presencia de huellas en una capa del acantilado en la que se aprecian rastros que atribuyeron a la mula. En 1410 se construyó en ese lugar la Ermida da Memoria, que actualmente forma parte del Santuário de Nossa Senhora do Cabo o da Pedra da Mua, que es objeto de peregrinaciones marianas. En el interior de dicha ermita se colocó en el siglo XVIII un mural cerámico que representa la leyenda. Hoy en día esas huellas se

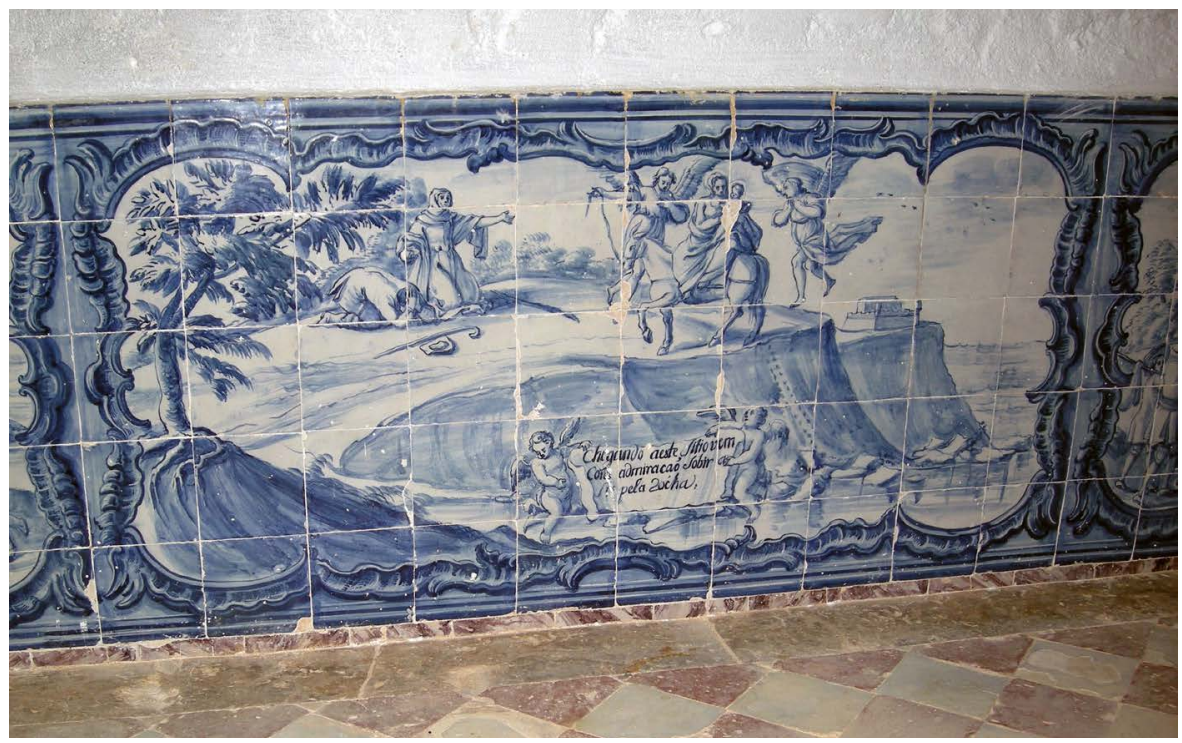


interpretan, en su mayoría, como icnitas producidas por dinosaurios saurópodos ( $y$, en menor medida, por terópodos) en el Jurásico Tardío, por lo que el embaldosado cerámico representaría la primera ilustración sobre icnitas de dinosaurios realizada en el mundo (SANTOS, 2003).

En España se conoce la existencia de poblados celtibéricos y de centros monacales de los siglos IX y X cerca de yacimientos con icnitas de dinosaurios en La Rioja Baja. Las necrópolis de Regumiel de la Sierra y Revenga en Burgos se sitúan en areniscas del Grupo Urbión (Cretácico Inferior), próximas a huellas tridáctilas (MORATALLA; SANZ; JIMÉNEZ, 1997). Sin embargo, no se conocen las interpretaciones de las icnitas que pudieron desarrollar esas culturas. Posteriormente y durante siglos, en la cultura popular española se han vinculado huellas de dinosaurios con el paso de Santiago el Mayor: en numerosas poblaciones de la mitad norte peninsular se relacionaban las marcas de las rocas, que resultaban inexplicables tanto para la mentalidad campesina como para la erudita de la época, con las huellas de su fabuloso caballo volador. Este proceso de vinculación debió de producirse durante la etapa de popularidad del santo en el siglo XI para empezar a decaer con la difusión de las ideas ilustradas del siglo XVIII y desaparecer en el siglo XIX, momento en el que la influencia racionalista y naturalista de la ciencia cambió la interpretación de los fósiles. A las huellas fósiles de tres dedos, en lugares como Munilla en La Rioja, Bretún en Soria o Regumiel de la Sierra en Burgos, se les han atribuido orígenes fantásticos relacionados con gallinas gigantes encantadas por los moros, o con las brujas, o con un águila real gigantesca que rapiñaba a los niños y los ganados de la zona. En el caso concreto de Bretún, las capas con huellas de dinosaurio de la localidad se interpretaban por los vecinos como un antiguo corral

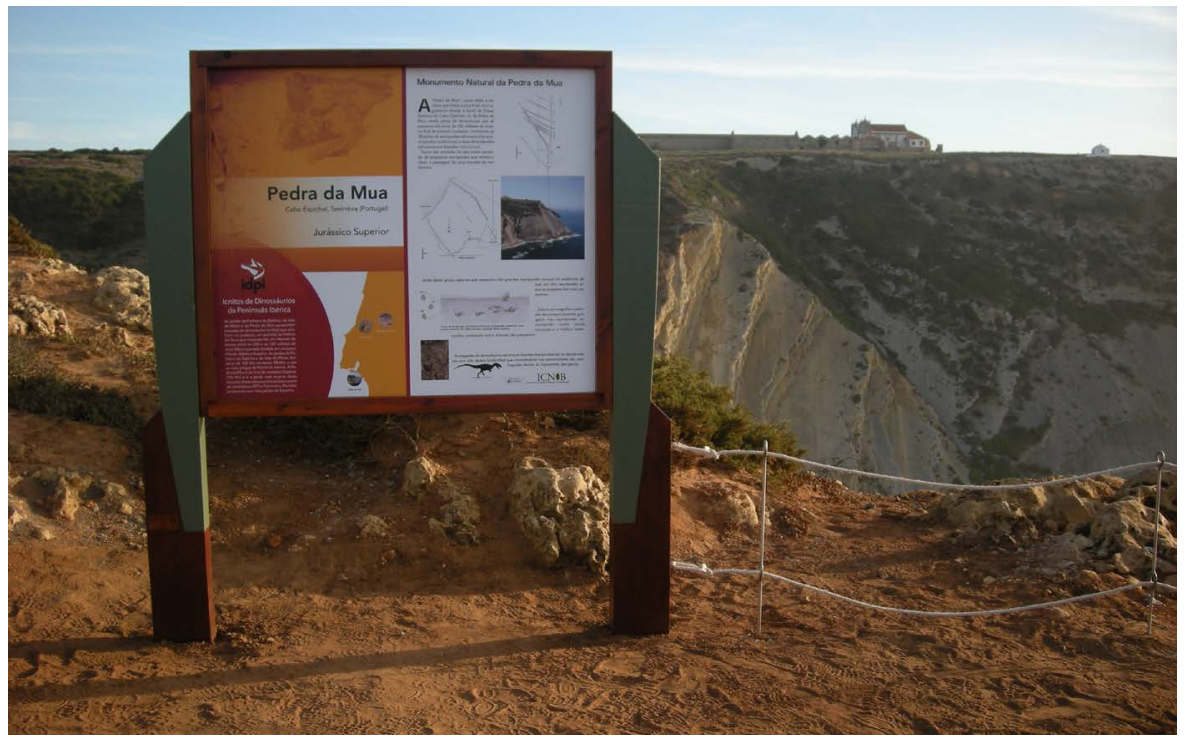

Interpretación del yacimiento de Pedra da Mua en Sesimbra, que se sitúa en el acantilado sobre el que se construyó la Ermida da Memoria 
donde los primeros habitantes del pueblo guardaban sus palomas y ganados (AGUIRREZABALA; VIERA, 1980; MORATALLA; SANZ; JIMÉNEZ, 1997).

Actualmente, cada vez es más habitual el hallazgo de restos de dinosaurios a lo largo de la geografía ibérica. Así, se han documentado centenares de yacimientos con restos directos -elementos del esqueleto- o indirectos -aquellos otros que nos muestran el resultado de su actividad en vida, como huellas, huevos o coprolitos- de estos vertebrados (ORTEGA; ESCASO; GASULLA et ál., 2006). Sin embargo, el esplendor actual en lo que a la dinosauriología de la Península Ibérica se refiere se comprende por la escasa tradición paleontológica en dinosaurios llevada a cabo siglos atrás, cuando el conocimiento de los "lagartos terribles" en otros lugares del mundo se encontraba mucho más avanzado. Así, mientras que ya en la primera mitad del siglo XIX se habían descrito en el Reino Unido dinosaurios como el carnívoro Megalosaurus (1824) o los fitófagos (comedores de plantas), Iguanodon (1825) e Hylaeosaurus (1833), y donde ya en 1842 se había propuesto por Owen el término "dinosaurio", en la Península Ibérica aún no se había realizado ninguna investigación científica relevante.

Los primeros fósiles de dinosaurios encontrados en Portugal fueron dos dientes de terópodo descubiertos en Porto das Barcas cerca de Lourinhã en 1863 (ANTUNES; MATEUS, 2003) y otros encontrados posteriormente fueron descritos por Sauvage (1897-1898). En 1884 se observaron icnitas de dinosaurios cerca de Cabo Mondego y las describió Gomes en 1916.

La Paleontología de dinosaurios en España también comenzó con el siglo XIX bien avanzado, en 1872, cuando Juan Vilanova y Piera (el primer catedrático de Geología y Paleontología español, de la Universidad Central de Madrid) citó textualmente en su Compendio de Geología, tras mencionar varios restos de un reptil colosal en Morella (Castellón): "También poseo dos huesos largos, que probablemente pertenecen al Ignanodon (sic) Mantelli que, procedentes de Utrillas, me mandó hace poco el distinguido médico de Montalbán D. Jerónimo Balduque". Comunicó esos hallazgos a la Sociedad Española de Historia Natural en 1873 y hoy en día se sabe que los dos fragmentos de huesos asignados por Vilanova al dinosaurio comedor de plantas Iguanodon probablemente formaban parte de una tibia de un dinosaurio carnívoro (PEREDA-SUBERBIOLA; RUIZ-OMEÑACA, 2005). De tal manera que hace casi 150 años se produjo el pistoletazo de salida de la historia de los hallazgos de restos de dinosaurios en España. No obstante, sería injusto no referirse a la mención por Guillermo Schulz (en su obra Descripción Geológica de Asturias, 1858) del fósil que en primera instancia se asignó a un diente de tiburón y que posteriormente, en 1873, se identificó como perteneciente al dinosaurio terópodo Megalosaurus, según Justo Egozcue. Desgraciadamente todos estos fósiles están desaparecidos, si bien de los de Utrillas se conserva un dibujo realizado por el paleon- 
tólogo castellonense José Royo Gómez alrededor de la década de 1920 (PEREDA-SUBERBIOLA; RUIZ-OMEÑACA, 2005). Por lo tanto, durante la totalidad del siglo XIX el estudio de los dinosaurios en España resultó muy poco fructífero y se desarrolló escasamente. Sin embargo, las publicaciones sobre yacimientos se han multiplicado extraordinariamente en casi todas las comunidades autónomas españolas y se han descrito centena-

Tabla 1. Listado de géneros y especies de dinosaurios terópodos de la Península Ibérica

\begin{tabular}{|c|c|c|c|c|c|}
\hline TAXÓN & FORMACIÓN & ED/AD & LOCALIDAD & CLASIFICACIÓN & REFERENCIA \\
\hline $\begin{array}{l}\text { Noguerornis } \\
\text { gonzalesi }\end{array}$ & $\begin{array}{l}\text { Calizas } \\
\text { litográficas del } \\
\text { Montsec }\end{array}$ & Barremiense & $\begin{array}{l}\text { El Montsec } \\
\text { (Lérida) }\end{array}$ & Euenantiornithes & Lacasa-Ruiz, 1989 \\
\hline Concornis lacustris & $\begin{array}{l}\text { Calizas de la } \\
\text { Huérguina }\end{array}$ & $\begin{array}{l}\text { Barremiense } \\
\text { superior }\end{array}$ & $\begin{array}{l}\text { Las Hoyas } \\
\text { (Cuenca) }\end{array}$ & Euenantiornithes & $\begin{array}{l}\text { Sanz, Buscalioni, } \\
1992\end{array}$ \\
\hline Eoalulavis hoyasi & $\begin{array}{l}\text { Calizas de la } \\
\text { Huérguina }\end{array}$ & $\begin{array}{l}\text { Barremiense } \\
\text { superior }\end{array}$ & $\begin{array}{l}\text { Las Hoyas } \\
\text { (Cuenca) }\end{array}$ & Euenantiornithes & Sanz et ál., 1996 \\
\hline $\begin{array}{l}\text { Iberomesornis } \\
\text { romerali }\end{array}$ & $\begin{array}{l}\text { Calizas de la } \\
\text { Huérguina }\end{array}$ & $\begin{array}{l}\text { Barremiense } \\
\text { superior }\end{array}$ & $\begin{array}{l}\text { Las Hoyas } \\
\text { (Cuenca) }\end{array}$ & Euenantiornithes & $\begin{array}{l}\text { Sanz y Bonaparte, } \\
1992\end{array}$ \\
\hline $\begin{array}{l}\text { Pelecanimimus } \\
\text { polyodon }\end{array}$ & $\begin{array}{l}\text { Calizas de la } \\
\text { Huérguina }\end{array}$ & $\begin{array}{l}\text { Barremiense } \\
\text { superior }\end{array}$ & $\begin{array}{l}\text { Las Hoyas } \\
\text { (Cuenca) }\end{array}$ & Ornithomimosauria & $\begin{array}{l}\text { Pérez-Moreno et } \\
\text { ál., } 1994\end{array}$ \\
\hline $\begin{array}{l}\text { Concavenator } \\
\text { corcovatus }\end{array}$ & $\begin{array}{l}\text { Calizas de la } \\
\text { Huérguina }\end{array}$ & $\begin{array}{l}\text { Barremiense } \\
\text { superior }\end{array}$ & $\begin{array}{l}\text { Las Hoyas } \\
\text { (Cuenca) }\end{array}$ & Carcharodontosauria & Ortega et ál., 2010 \\
\hline $\begin{array}{l}\text { Camarillasaurus } \\
\text { cirugedae }\end{array}$ & Camarillas & $\begin{array}{l}\text { Barremiense } \\
\text { inferior }\end{array}$ & $\begin{array}{l}\text { Camarillas } \\
\text { (Teruel) }\end{array}$ & Ceratosauria & $\begin{array}{l}\text { Sáchez-Hernández } \\
\text { y Benton, } 2014\end{array}$ \\
\hline $\begin{array}{l}\text { Lourinhanosaurus } \\
\text { antunesi }\end{array}$ & Sobral & $\begin{array}{l}\text { Kimmeridgiense- } \\
\text { Titoniense inferior }\end{array}$ & Peralta (Lourinhã) & $\begin{array}{l}\text { Metriacanthosauri- } \\
\text { dae }\end{array}$ & $\begin{array}{l}\text { Mateus, 1998; } \\
\text { Malafaia, 2017 }\end{array}$ \\
\hline $\begin{array}{l}\text { Allosarurus cf. } \\
\text { europaeus }\end{array}$ & $\begin{array}{l}\text { Bombarral } \\
\text { (=Lourinhã) }\end{array}$ & Titoniense & Andrés (Pombal) & Allosauroidea & Malafaia, 2017 \\
\hline $\begin{array}{l}\text { Allosaurus } \\
\text { europaeus }\end{array}$ & $\begin{array}{l}\text { Praia da } \\
\text { Amoreira-Porto } \\
\text { Novo }\end{array}$ & $\begin{array}{l}\text { Kimmeridgiense } \\
\text { superior- } \\
\text { Titoniense inferior }\end{array}$ & $\begin{array}{l}\text { Praia de Vale } \\
\text { Frades } \\
\text { (Lourinhã) }\end{array}$ & Allosauroidea & $\begin{array}{l}\text { Malafaia, 2017; } \\
\text { Mateus et ál., } 2006\end{array}$ \\
\hline $\begin{array}{l}\text { Ceratosaurus aff. } \\
\text { nasicornis }\end{array}$ & $\begin{array}{l}\text { Praia da } \\
\text { Amoreira-Porto } \\
\text { Novo, Freixial y } \\
\text { Sobral }\end{array}$ & $\begin{array}{l}\text { Kimmeridgiense } \\
\text { superior- } \\
\text { Titoniense } \\
\text { superior }\end{array}$ & $\begin{array}{l}\text { Valmitão } \\
\text { (Ribamar, } \\
\text { Lourinhã) }\end{array}$ & Ceratosauria & Malafaia, 2017 \\
\hline Ceratosaurus sp. & $\begin{array}{l}\text { Praia da } \\
\text { Amoreira-Porto } \\
\text { Novo }\end{array}$ & $\begin{array}{l}\text { Kimmeridgiense } \\
\text { superior- } \\
\text { Titoniense inferior }\end{array}$ & $\begin{array}{l}\text { Torres Vedras, } \\
\text { Lourinhã y } \\
\text { Peniche }\end{array}$ & Ceratosauria & $\begin{array}{l}\text { Malafaia et ál., } \\
\text { 2015; Malafaia, } \\
2017\end{array}$ \\
\hline $\begin{array}{l}\text { Torvosaurus } \\
\text { gurneyi }\end{array}$ & $\begin{array}{l}\text { Praia da } \\
\text { Amoreira-Porto } \\
\text { Novo }\end{array}$ & $\begin{array}{l}\text { Kimmeridgiense } \\
\text { superior- } \\
\text { Titoniense inferior }\end{array}$ & $\begin{array}{l}\text { Praia de Vermelha } \\
\text { (Peniche) }\end{array}$ & Megalosauroidea & $\begin{array}{l}\text { Hendrickx, Mateus, } \\
\text { 2014; Malafaia et } \\
\text { ál., } 2017\end{array}$ \\
\hline Torvosaurus sp. & $\begin{array}{l}\text { Praia da } \\
\text { Amoreira-Porto } \\
\text { Novo, Alcobaça y } \\
\text { Sobral }\end{array}$ & $\begin{array}{l}\text { Kimmeridgiense } \\
\text { superior- } \\
\text { Titoniense inferior }\end{array}$ & $\begin{array}{l}\text { Torres Vedras, } \\
\text { Lourinhã, Peniche, } \\
\text { Caldas da Rainha }\end{array}$ & Megalosauroidea & $\begin{array}{l}\text { Malafaia et ál., } \\
2017\end{array}$ \\
\hline $\begin{array}{l}\text { Aviatyrannis } \\
\text { jurassica }\end{array}$ & Alcobaça & Kimmeridgiense & Guimarota (Leiria) & Tyrannosauroidea & $\begin{array}{l}\text { Rauhut, 2003; } \\
\text { Malafaia, 2017 }\end{array}$ \\
\hline
\end{tabular}




\begin{tabular}{|c|c|c|c|c|c|}
\hline TAXÓN & FORMACIÓN & $E \mathrm{DAD}$ & LOCAILIDAD & CLASIFICACIÓN & REEFERENCIA \\
\hline $\begin{array}{l}\text { Lohuecotitan } \\
\text { pandafilandi }\end{array}$ & $\begin{array}{l}\text { Villalba de la } \\
\text { Sierra }\end{array}$ & $\begin{array}{l}\text { Campaniense- } \\
\text { Maastrichtiense }\end{array}$ & Fuentes (Cuenca) & Titanosauria & $\begin{array}{l}\text { Díez-Díaz et ál., } \\
2016\end{array}$ \\
\hline $\begin{array}{l}\text { Lirainosaurus } \\
\text { astibiae }\end{array}$ & & Campaniense & Laño (Burgos) & Titanosauria & Sanz et ál., 1999 \\
\hline $\begin{array}{l}\text { Demandasaurus } \\
\text { darwini }\end{array}$ & $\begin{array}{l}\text { Castrillo de la } \\
\text { Reina }\end{array}$ & $\begin{array}{l}\text { Barremiense } \\
\text { superior-Aptiense } \\
\text { inferior }\end{array}$ & $\begin{array}{l}\text { Salas de los Infan- } \\
\text { tes (Burgos) }\end{array}$ & Rebbachisauridae & Torcida et ál., 2011 \\
\hline $\begin{array}{l}\text { Europatitan } \\
\text { eastwoodi }\end{array}$ & $\begin{array}{l}\text { Castrillo de la } \\
\text { Reina }\end{array}$ & $\begin{array}{l}\text { Barremiense } \\
\text { superior-Aptiense } \\
\text { inferior }\end{array}$ & $\begin{array}{l}\text { Salas de los Infan- } \\
\text { tes (Burgos) }\end{array}$ & Titanosauriformes & Torcida et ál., 2017 \\
\hline $\begin{array}{l}\text { Tastavinsaurus } \\
\text { sanzi }\end{array}$ & Chert y Forcall & $\begin{array}{l}\text { Barremiense } \\
\text { superior }\end{array}$ & $\begin{array}{l}\text { Peñarroya de } \\
\text { Tastavins y El } \\
\text { Castellar (Teruel) }\end{array}$ & Titanosauriformes & $\begin{array}{l}\text { Canudo et ál., } \\
\text { 2008; Royo et ál., } \\
2012\end{array}$ \\
\hline $\begin{array}{l}\text { Soriatitan } \\
\text { golmayensis }\end{array}$ & Golmayo & $\begin{array}{l}\text { Hauteriviense- } \\
\text { Barremiense } \\
\text { inferior }\end{array}$ & Golmayo (Soria) & Titanosauriformes & $\begin{array}{l}\text { Royo-Torres et ál., } \\
2017\end{array}$ \\
\hline $\begin{array}{l}\text { Turiasaurus } \\
\text { riodevensis }\end{array}$ & $\begin{array}{l}\text { Villar del Arzo- } \\
\text { bispo }\end{array}$ & $\begin{array}{l}\text { Kimeridgiense- } \\
\text { Titoniense }\end{array}$ & Riodeva (Teruel) & Turiasauria & $\begin{array}{l}\text { Royo-Torres et ál., } \\
2006\end{array}$ \\
\hline $\begin{array}{l}\text { Losillasaurus } \\
\text { giganteus }\end{array}$ & $\begin{array}{l}\text { Villar del Arzo- } \\
\text { bispo }\end{array}$ & $\begin{array}{l}\text { Kimeridgiense- } \\
\text { Titoniense }\end{array}$ & $\begin{array}{l}\text { Alpuente (Valen- } \\
\text { cia) }\end{array}$ & Turiasauria & $\begin{array}{l}\text { Casanovas et ál., } \\
2001\end{array}$ \\
\hline $\begin{array}{l}\text { Aragosaurus } \\
\text { ischiaticus }\end{array}$ & $\begin{array}{l}\text { Villar del Arzo- } \\
\text { bispo }\end{array}$ & $\begin{array}{l}\text { Kimeridgiense- } \\
\text { Titoniense }\end{array}$ & Galve (Teruel) & Macronaria & $\begin{array}{l}\text { Sanz et ál., 1987; } \\
\text { Royo et ál., } 2014\end{array}$ \\
\hline $\begin{array}{l}\text { Galveosaurus } \\
\text { herreroi }\end{array}$ & $\begin{array}{l}\text { Villar del Arzo- } \\
\text { bispo }\end{array}$ & $\begin{array}{l}\text { Kimeridgiense- } \\
\text { Titoniense }\end{array}$ & Galve (Teruel) & Titanosauriformes & $\begin{array}{l}\text { Sánchez- } \\
\text { Hernández, } 2005\end{array}$ \\
\hline $\begin{array}{l}\text { Lusotitan } \\
\text { atalayensis }\end{array}$ & Sobral & $\begin{array}{l}\text { Kimmeridgiense } \\
\text { superior-Titoniense } \\
\text { inferior }\end{array}$ & Peralta (Atalaia) & Titanosauriformes & $\begin{array}{l}\text { Lapparent y } \\
\text { Zbyszewski, 1957; } \\
\text { Antunes y Mateus, } \\
2003\end{array}$ \\
\hline $\begin{array}{l}\text { Lourinhasaurus } \\
\text { alenquerensis }\end{array}$ & Sobral & $\begin{array}{l}\text { Kimmeridgiense } \\
\text { superior-Titoniense } \\
\text { inferior }\end{array}$ & $\begin{array}{l}\text { Moinho do Carmo } \\
\text { (Alenquer) }\end{array}$ & Macronaria & $\begin{array}{l}\text { Lapparent y } \\
\text { Zbyszewski, 1957; } \\
\text { Dantas et ál., } 1998\end{array}$ \\
\hline $\begin{array}{l}\text { Dinheirosaurus } \\
\text { lourinhanensis }\end{array}$ & $\begin{array}{l}\text { Praia da } \\
\text { Amoreira-Porto } \\
\text { Novo }\end{array}$ & $\begin{array}{l}\text { Kimmeridgiense } \\
\text { superior-Titoniense } \\
\text { inferior }\end{array}$ & $\begin{array}{l}\text { Moinho do Carmo } \\
\text { (Alenquer) }\end{array}$ & Diplodocidae & $\begin{array}{l}\text { Bonaparte y } \\
\text { Mateus, } 1999\end{array}$ \\
\hline Zby atlanticus & $\begin{array}{l}\text { Praia da } \\
\text { Amoreira-Porto } \\
\text { Novo }\end{array}$ & $\begin{array}{l}\text { Kimmeridgiense } \\
\text { superior-Titoniense } \\
\text { inferior }\end{array}$ & $\begin{array}{l}\text { Vale Pombas } \\
\text { (Lourinhã) }\end{array}$ & Turiasauria & Mateus et ál., 2014 \\
\hline
\end{tabular}

Tabla 2. Listado de géneros y especies de dinosaurios saurópodos de la Península Ibérica

res de nuevos hallazgos. Así, mientras que en 1984 en España se conocía apenas una treintena de enclaves fosilíferos con dinosaurios y el número de publicaciones no sobrepasaba el medio centenar, hoy se contabiliza más de medio millar de yacimientos importantes y el número de publicaciones de calado internacional se ha multiplicado exponencialmente. De hecho, desde que en 1916 se publicó el primer trabajo sobre huellas de dinosaurios en la Península Ibérica (GOMES, 1916), se ha documentado casi un cuarto de 


\begin{tabular}{|c|c|c|c|c|c|}
\hline TAXÓN & FORMACIÓN & EDAD & LOCAILID/AD & CLASIFICACIÓN & REEEEERENCIA \\
\hline $\begin{array}{l}\text { Struthiosaurus } \\
\text { sp. }\end{array}$ & Vitoria & $\begin{array}{l}\text { Campaniense } \\
\text { superior }\end{array}$ & Laño (Burgos) & Nodosauridae & $\begin{array}{l}\text { Pereda Suberbiola, } \\
1999\end{array}$ \\
\hline $\begin{array}{l}\text { Europelta } \\
\text { carbonensis }\end{array}$ & Escucha & $\begin{array}{l}\text { Albiense } \\
\text { inferior }\end{array}$ & Ariño (Teruel) & Nodosauridae & $\begin{array}{l}\text { Kirkland et ál., } \\
2013\end{array}$ \\
\hline Polacanthus sp. & Morella & $\begin{array}{l}\text { Barremiense } \\
\text { superior }\end{array}$ & $\begin{array}{l}\text { Morella } \\
\text { (Castellón) }\end{array}$ & Polacanthidae & $\begin{array}{l}\text { Pereda Suberbiola } \\
\text { et ál., 2007; } \\
\text { Gasulla et ál., } 2011\end{array}$ \\
\hline $\begin{array}{l}\text { Dacentrurus } \\
\text { armatus }\end{array}$ & $\begin{array}{l}\text { Villar del Arzo- } \\
\text { bispo }\end{array}$ & $\begin{array}{l}\text { Kimmeridgiense- } \\
\text { Titoniense }\end{array}$ & $\begin{array}{l}\text { Varias } \\
\text { localidades }\end{array}$ & Stegosauria & Cobos et ál., 2010 \\
\hline $\begin{array}{l}\text { "Miragaia } \\
\text { longicollum" }\end{array}$ & Sobral & $\begin{array}{l}\text { Kimmeridgiense } \\
\text { superior-Titoniense } \\
\text { inferior }\end{array}$ & Lourinhã & Stegosauria & $\begin{array}{l}\text { Mateus et ál., } \\
\text { 2009; Cobos y } \\
\text { Gascó, } 2013\end{array}$ \\
\hline $\begin{array}{l}\text { Dracopelta } \\
\text { zbyszewskii }\end{array}$ & & Kimmeridgiense & $\begin{array}{l}\text { Assenta } \\
\text { (Torres Vedras) }\end{array}$ & Ankylosauria & Galton, 1980 \\
\hline
\end{tabular}

Tabla 3. Listado de géneros y especies de dinosaurios tireóforos de la Península Ibérica

millar de yacimientos de este tipo y se han catalogado más de 22.000 huellas (FCPTD, 2009). En total, se contabilizan 40 nuevas especies de dinosaurios propuestas con material de España y Portugal (ver tablas 1 a 4) y se han defendido 29 tesis doctorales sobre fósiles de dinosaurios ibéricos en universidades de España y Portugal (MORATALLA, 1993; SANTOS, 2003; PÉREZ PÉREZ, 2004; COMPANY, 2004; MATEUS, 2005; ROYO-TORRES, 2006; 2009a; RUIZ-OMEÑACA, 2006; TORICES-HERNÁNDEZ, 2007; BARCO, 2009; VILA, 2010; COBOS, 2011; CRUZADO-CABALLERO, 2012; TORCIDA, 2012; CASTANERA, 2013; DÍEZ-DÍAZ, 2013; DÍAZ-MARTÍNEZ, 2013; ESCASO, 2014; MORENO-AZANZA, 2014; GASCA, 2015; GASCÓ, 2015; GASULLA, 2015; GARCÍA-ORTÍZ, 2016; MOCHO, 2016; PIÑUELA, 2016; RAZZOLINI, 2016; SUÑER, 2016; CUESTA, 2017; MALAFAIA, 2017; VERDÚ, 2017).

Las sucesiones estratigráficas en las que yace, o de las que proviene, este extenso registro son muy completas en intervalos que abarcan desde el Jurásico Medio portugués hasta el Cretácico terminal del Pirineo español, con excelente exposición de los afloramientos. Además, esta sucesión reúne a casi todos los tipos de rocas y de medios sedimentarios en los que se han descrito icnitas de dinosaurios, asociadas en la mayoría de ocasiones a importantes yacimientos de restos directos de estos vertebrados. El conjunto aporta una valiosa información científica sobre la evolución y modos de vida de los dinosaurios en un área muy restringida: la Placa Ibérica.

Un clima predominantemente templado y seco, que condiciona una escasa cobertera vegetal, una gran variedad de entornos geológicos y las características fisiográficas existentes en la Península Ibérica, favorecen la exposición de una gran cantidad y calidad de afloramientos con icnitas y con 


\begin{tabular}{|c|c|c|c|c|c|}
\hline TAXÓN & FORMACIÓN & EDAD & LOCAILIDAD & CLASIFICACIÓN & REFERENCIA \\
\hline $\begin{array}{l}\text { Koutalisaurus } \\
\text { kohlerorum }\end{array}$ & Tremp & $\begin{array}{l}\text { Maastrichtiense } \\
\text { superior }\end{array}$ & $\begin{array}{l}\text { Abella de la Conca } \\
\text { (Lérida) }\end{array}$ & Lambeosarinae & $\begin{array}{l}\text { Prieto-Márquez et } \\
\text { ál., } 2006\end{array}$ \\
\hline $\begin{array}{l}\text { Arenysaurus } \\
\text { ardevoli }\end{array}$ & Tremp & $\begin{array}{l}\text { Maastrichtiense } \\
\text { superior }\end{array}$ & Arén (Huesca) & Lambeosarinae & $\begin{array}{l}\text { Pereda-Suberbiola } \\
\text { et ál., } 2009\end{array}$ \\
\hline $\begin{array}{l}\text { Blasisaurus } \\
\text { canudoi }\end{array}$ & Arén & $\begin{array}{l}\text { Maastrichtiense } \\
\text { superior }\end{array}$ & Arén (Huesca) & Lambeosarinae & $\begin{array}{l}\text { Cruzado-Caballero } \\
\text { et ál., } 2010\end{array}$ \\
\hline $\begin{array}{l}\text { Pararhabdodon } \\
\text { isonensis }\end{array}$ & Tremp & Maastrichtiense & Isona (Lérida) & Lambeosarinae & $\begin{array}{l}\text { Casanovas- } \\
\text { Cladellas et ál., } \\
1993\end{array}$ \\
\hline Rhabdodon sp. & Vitoria & $\begin{array}{l}\text { Campaniense } \\
\text { superior }\end{array}$ & Laño (Burgos) & Iguanodontia & $\begin{array}{l}\text { Pereda-Suberbiola } \\
\text { y Sanz, } 1999\end{array}$ \\
\hline $\begin{array}{l}\text { Proa } \\
\text { valdearinnoensis }\end{array}$ & Escucha & Albiense inferior & Ariño (Teruel) & Ornithopoda & $\begin{array}{l}\text { McDonald et ál., } \\
2012\end{array}$ \\
\hline $\begin{array}{l}\text { Morelladon } \\
\text { beltrani }\end{array}$ & Morella & $\begin{array}{l}\text { Barremiense } \\
\text { superior }\end{array}$ & Morella (Castellón) & Ornithopoda & $\begin{array}{l}\text { Gasulla et ál., } \\
2015\end{array}$ \\
\hline $\begin{array}{l}\text { Mantelisaurus } \\
\text { atherfieldensis }\end{array}$ & Morella & $\begin{array}{l}\text { Barremiense } \\
\text { superior }\end{array}$ & Morella (Castellón) & Ornithopoda & Gasulla, 2015 \\
\hline $\begin{array}{l}\text { Iguanodon } \\
\text { bernissartensis }\end{array}$ & Morella & $\begin{array}{l}\text { Barremiense } \\
\text { superior }\end{array}$ & Morella (Castellón) & Ornithopoda & $\begin{array}{l}\text { Gasulla et ál., } \\
2014\end{array}$ \\
\hline $\begin{array}{l}\text { Iguanodon } \\
\text { galvensis }\end{array}$ & Camarillas & $\begin{array}{l}\text { Barremiense } \\
\text { superior }\end{array}$ & Galve (Teruel) & Ornithopoda & $\begin{array}{l}\text { Verdú et ál., 2015, } \\
2017 a\end{array}$ \\
\hline $\begin{array}{l}\text { "Delapparentia } \\
\text { turolensis" }\end{array}$ & Camarillas & $\begin{array}{l}\text { Barremiense } \\
\text { superior }\end{array}$ & Galve (Teruel) & Ornithopoda & $\begin{array}{l}\text { Ruiz-Omeñaca, } \\
\text { 2011; Verdú et ál., } \\
\text { 2017b }\end{array}$ \\
\hline $\begin{array}{l}\text { Gideonmantellia } \\
\text { amosanjuanae }\end{array}$ & Camarillas & $\begin{array}{l}\text { Barremiense } \\
\text { superior }\end{array}$ & Galve (Teruel) & Ornithopoda & $\begin{array}{l}\text { Ruiz-Omeñaca et } \\
\text { ál., } 2012\end{array}$ \\
\hline $\begin{array}{l}\text { Magnamanus } \\
\text { soriaensis }\end{array}$ & Golmayo & $\begin{array}{l}\text { Hauteriviense- } \\
\text { Barremiense }\end{array}$ & Golmayo (Soria) & Ornithopoda & $\begin{array}{l}\text { Fuentes-Vidarte et } \\
\text { ál., } 2016\end{array}$ \\
\hline $\begin{array}{l}\text { Draconyx } \\
\text { loureiroi }\end{array}$ & "Bombarral" & Titoniense & $\begin{array}{l}\text { Vale Frades } \\
\text { (Lourinhã) }\end{array}$ & Styracosterna & $\begin{array}{l}\text { Mateus y Antunes, } \\
2001\end{array}$ \\
\hline $\begin{array}{l}\text { Uteodon } \\
\text { aphanoecetes }\end{array}$ & $\begin{array}{l}\text { Praia da } \\
\text { Amoreira-Porto } \\
\text { Novo }\end{array}$ & $\begin{array}{l}\text { Kimmeridgiense } \\
\text { superior }\end{array}$ & $\begin{array}{l}\text { Praia da Corva } \\
\text { (Torres Vedras) }\end{array}$ & Styracosterna & $\begin{array}{l}\text { McDonald, 2011; } \\
\text { Escaso, } 2014\end{array}$ \\
\hline $\begin{array}{l}\text { Eousdryosaurus } \\
\text { nanohallucis }\end{array}$ & Alcobaça & $\begin{array}{l}\text { Kimmeridgiense } \\
\text { superior }\end{array}$ & $\begin{array}{l}\text { Porto das Barcas } \\
\text { (Lourinhã) }\end{array}$ & Dryosauridae & $\begin{array}{l}\text { Escaso et ál., } \\
2014\end{array}$ \\
\hline
\end{tabular}

Tabla 4. Listado de géneros y especies de dinosaurios ornitópodos de la Península Ibérica

restos directos. El área geográfica en la que se sitúan estos yacimientos se relaciona con la emersión de cuencas sedimentarias próximas entre sí y en continua evolución durante el Mesozoico, en las que están presentes las características sedimentarias, paleoambientales y paleogeográficas necesarias para que se generase una gran variedad de yacimientos. La excepcional continuidad del registro sedimentario y la variedad de procesos geológicos asociados ha supuesto encontrar yacimientos en la mayoría de las facies y ambientes sedimentarios posibles. Así, encontramos yacimientos tanto en 
depósitos fluviales como litorales del área supra e intermareal y en ambientes palustres, lacustres y deltaicos, todos ellos en zonas de alta actividad sedimentaria.

Los yacimientos conocidos contienen ejemplos característicos que suministran valiosa información para inferir qué animales vivieron o produjeron las huellas y su comportamiento individual y de grupo (MORATALLA, 1993; PÉREZ-LORENTE, 2003; GARCÍA-RAMOS; PIÑUELA; LIRES, 2006; TORCIDA, 2006; ANDRÉS; ALCALÁ; BARCO et ál., 2007; FCPTD, 2009; POZA; SUÑER; SANTOS-CUBEDO et ál., 2008; SANTOS; MORATALLA; ROYO-TORRES et ál., 2009, etc.). Entre los centenares de yacimientos de icnitas conocidos, varios destacan por el gran número de huellas (con más de 3.000) y de rastros (alguno de los cuales supera los $140 \mathrm{~m}$ de longitud), como son Vale de Meios en Portugal o El Peladillo y Fumanya en España, entre otros. También están representados casos de conservación excepcional en los que ha quedado fosilizada la impresión de la piel e incluso las marcas de deslizamiento sobre el barro, así como algunas huellas que con-
A la izquierda, el megayacimiento de icnitas de dinosaurio del Jurásico Medio de Vale de Meios (Santarém); a la derecha, Un pequeño sector de megayacimiento de icnitas de dinosaurios del Cretácico Tardío de Fumanya (Barcelona)
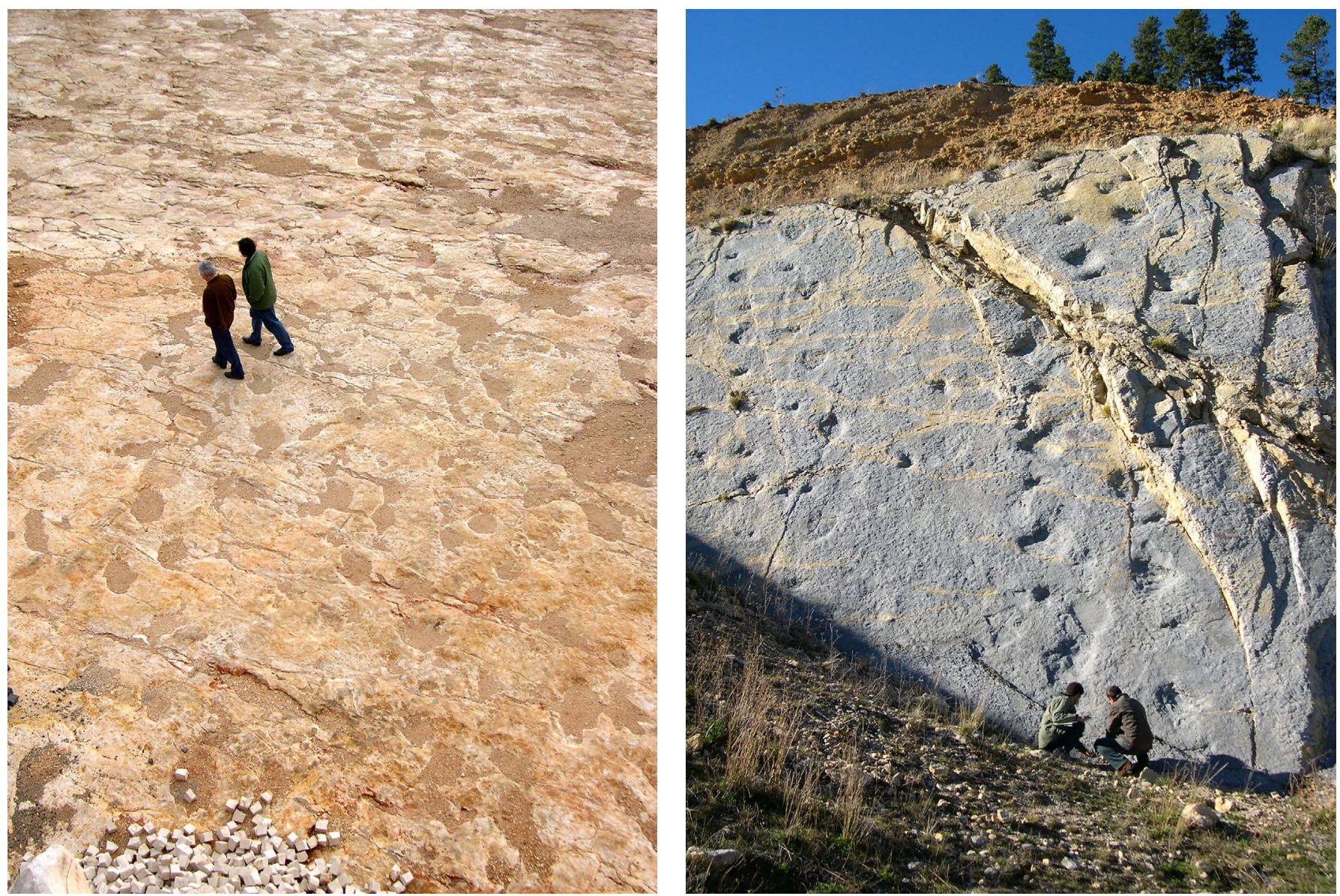
Icnita de Alcalá de la Selva (Teruel) que conserva completamente el pie del dinosaurio en forma de contramolde, así como su trayectoria en el interior del sedimento

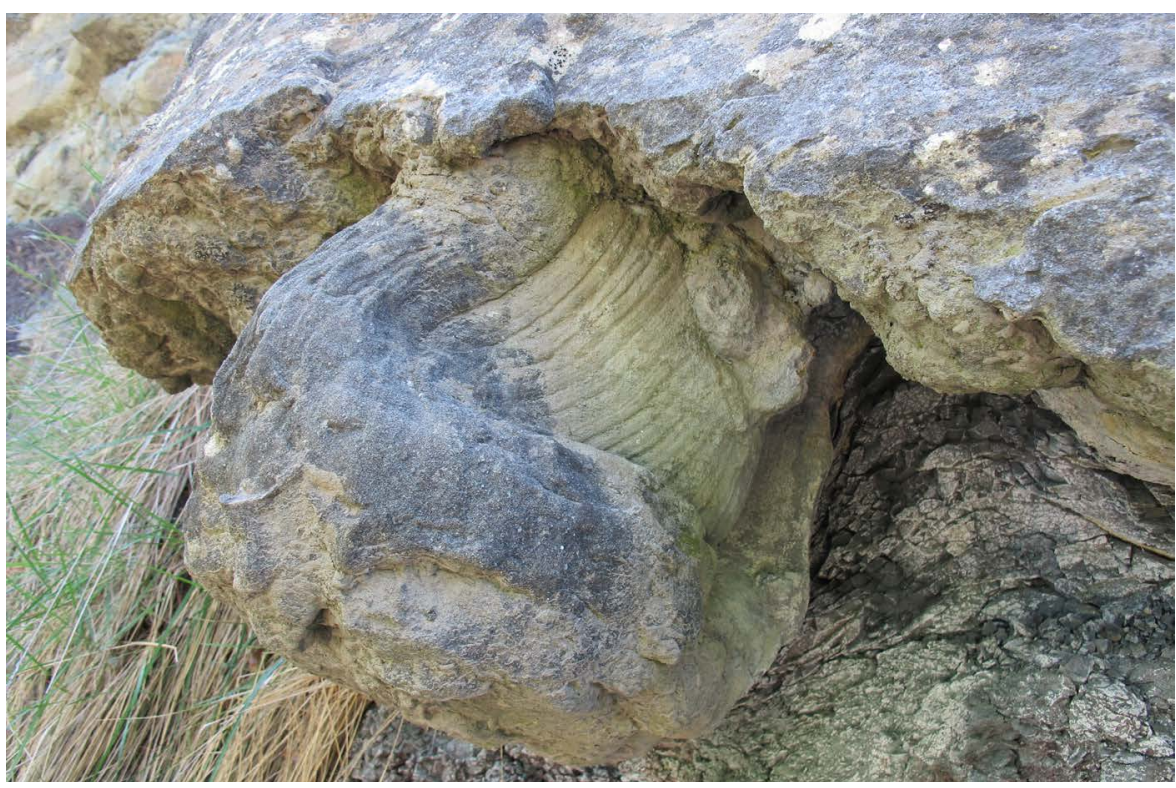

servan el pie del dinosaurio casi completo en forma de contramolde, como en los yacimientos Costalomo y Río Alcalá en España (HUERTA; TORCIDA; FARLOW et ál., 2012; COBOS; GASCÓ; ROYO-TORRES et ál., 2016).

\section{MARCO GEOLÓGICO GENERAL}

La Península Ibérica equivale geológicamente a la conocida como Placa Ibérica, que durante buena parte del Mesozoico ocupó una posición estratégica justamente en el centro de las principales áreas emergidas (primero en el supercontinente Pangea y también luego durante su división en Laurasia y Gondwana). Durante el Kimmeridgiense-Titoniense (Jurásico Tardío) funcionó como una isla de un conjunto mayor de islas europeas situadas entre Laurasia y Gondwana. La Placa Ibérica contenía varias cuencas sedimentarias con ambientes muy variados (lacustres, fluviales y deltaicos) como consecuencia de una fase de extensión relacionada con la apertura del Mar de Tethys (ancestro del actual Mar Mediterráneo) y del Océano Atlántico. Los vertebrados más estudiados que vivieron en estos ambientes fueron principalmente tortugas, cocodrilos y dinosaurios (estos últimos muy diversos y abundantes). Los dinosaurios que habitaron la Península Ibérica en el Jurásico Tardío eran similares a los hallados en otras formaciones jurásicas de África y Estados Unidos (MATEUS, 2006; ROYO-TORRES; COBOS; ABERASTURI et ál., 2009; COBOS; LOCKLEY; GASCÓ et ál., 2014; MOCHO, 2016; MALAFAIA, 2017). Sin embargo, su evolución en un ambiente de isla propició que tuvieran algunas particularidades, con taxones propios de diversos grupos (tablas 1-4): terópodos (ceratosaurios, alosau- 
roideos, megalosauroideos y tiranosauroideos), saurópodos (turiasaurios, diplodócidos, macronarios basales y titanosauriformes), ornitópodos (driosáuridos y camptosáuridos) y tireóforos (estegosaurios y anquilosaurios). Aunque los fósiles de dinosaurios más antiguos se registran en el Jurásico Medio, la mayoría se concentra en afloramientos del Jurásico Superior (Kimmeridgiense-Titoniense). Durante el Cretácico continuó la separación de las grandes masas continentales pero existieron conexiones esporádicas durante el Cretácico Temprano entre las islas del este europeo, Norteamérica y África (ROYO-TORRES; UPCHURCH; KIRKLAND et ál., 2017; ROYOTORRES; FUENTES; MEIJIDE et ál., 2017) que permitieron el intercambio de asociaciones de dinosaurios. El registro de dinosaurios es abundante especialmente en los intervalos Barremiense-Albiense (Cretácico Temprano) y, posteriormente, en el Campaniense-Maastrichtiense (Cretácico Tardío), como se resume en la tablas 1, 2, 3 y 4 . En el Barremiense se encuentran emblemáticas aves del grupo Enantiornithes (en Las Hoyas, Cuenca) y terópodos no avianos ornitomimosaurios, carcarodontosaurios y ceratosaurios. Los dinosaurios fitófagos más representativos eran los braquiosáuridos, rebaquisáuridos, iguanodontios y polacántidos. En el Albiense la fauna estuvo dominada principalmente por iguanodontios y nodosáuridos. Finalmente, en el Cretácico Tardío los ecosistemas estuvieron dominados por titanosaurios y hadrosaurios (ORTEGA; ESCASO; GASULLA et ál., 2006; GASULLA; ORTEGA; ESCASO et ál., 2006; VILA, 2010; CRUZADOCABALLERO, 2012).

La gran riqueza de restos directos e indirectos de dinosaurios en el mismo entorno espacial y temporal aporta a la Península Ibérica un interés especial para el estudio del registro fósil de las sucesiones de las faunas de dinosaurios. Esta abundante información dinosauriológica que se extiende desde el Jurásico Medio hasta el Cretácico más tardío permite considerar a la Península Ibérica como un gigantesco yacimiento de dinosaurios en el que se registran, a lo largo de dicho intervalo de tiempo geológico, los cambios evolutivos basados en restos directos y su reflejo en el registro icnológico. Por ello, esta zona geográfica constituye un referente para interpretar la distribución de los grandes grupos de dinosaurios a lo largo de los últimos 100 millones de años del Mesozoico en una zona con una posición paleogeográfica estratégica. A continuación se describe sucintamente la diversidad dinosauriológica de algunas de las zonas más representativas de España y Portugal.

\section{JURÁSICO MEDIO-JURÁSICO TARDÍO}

Exceptuando algunos datos aislados del Triásico y del Jurásico Temprano, los yacimientos representativos de los vestigios más antiguos de dinosaurios en la Península corresponden a icnitas del Jurásico Medio y se convier- 


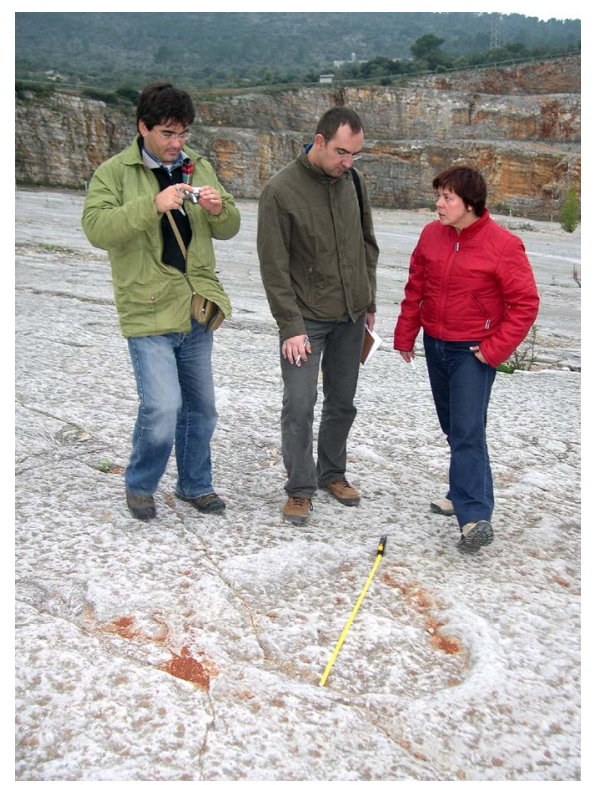

Polyonyx de Pedreira do Galinha (Santarém), un tipo de huella producido por un dinosaurio saurópodo, probablemente del grupo de los turiasaurios ten en muy frecuentes durante el Jurásico Tardío. En estas edades están bien representados a través de restos directos los eusaurópodos basales, diplodócidos, titanosauriformes basales y ornitópodos basales (camptosáuridos y driosáuridos), entre otros. Estos dinosaurios serían los productores de huellas saurópodas cuadrúpedas de rastros anchos y estrechos, ornitópodas bípedas de diferente tamaño y cuadrúpedas ocasionales, además de otras de productores terópodos con varias tallas atribuibles, por ejemplo, a alosaurios, espinosaurios, ceratosaurios y manirraptores. Entre los tireóforos destacan los estegosaurios con rastros cuadrúpedos. Esta fauna queda especialmente reflejada en el registro icnológico en varios yacimientos de Portugal, como Pedreira do Galinha (donde SANTOS; MORATALLA; ROYOTORRES, 2009 definieron el icnotaxón Polyonyx) o Vale de Meios, ambos del Jurásico Medio, y Pedra da Mua (LOCKLEY; MEYER; SANTOS, 1994; SANTOS, 2008), del Jurásico Tardío, así como en otros de España: Tereñes (PIÑUELA; GARCÍA-RAMOS; RUIZ OMEÑACA, 2007), Las Cerradicas (PÉREZ-LORENTE; CUENCA; AURELL et ál., 1997; CASTANERA; VILA; RAZZOLINI et ál., 2013) o El Castellar (COBOS; ROYO-TORRES; LUQUE et ál., 2010; COBOS; LOCKLEY; GASCÓ et ál., 2014; ALCALÁ; MAMPEL; ROYO-TORRES et ál., 2014), también del Jurásico Tardío.

La Cuenca Lusitánica de Portugal tiene su registro de dinosaurios más abundante a lo largo del Jurásico Tardío (Kimmeridgiense-Titoniense), un intervalo temporal equivalente al de algunas unidades con dinosaurios de la Cuencas Suribérica y del Maestrazgo de España (como es el caso de la Formación Villar del Arzobispo), por lo que comparten asociaciones faunísticas similares. La Cuenca Lusitánica se divide en diferentes subcuencas (Arruda, Bombarral y Turcifal) que se rellenaron con sedimentos de ambientes continentales y costeros que dieron lugar a diferentes formaciones, entre ellas Alcobaça, Praia da Amoreira-Porto Novo, Sobral, Freixial y Bombarral (MOCHO; ROYO-TORRES; ORTEGA, 2017; MOCHO; ROYO-TORRES; PIMENTEL et ál., 2017; MALAFAIA, 2017). Los dinosaurios representados pertenecen a los grupos de saurópodos, terópodos, ornitópodos y tireóforos. En lo que se refiere a restos directos, y en el primer grupo, los dinosaurios eusaurópodos no neosaurópodos incluyen especies con características primitivas, como Zby atlanticus (MATEUS; MANNION; UPCHURCH, 2014), similar a Turiasaurus riodevensis de la Formación Villar del Arzobispo (ROYOTORRES; COBOS; ALCALÁ, 2006). Entre los neosaurópodos se encuentra fauna afín a la del registro de dinosaurios de Norteamérica y África. Se han descrito diplodócidos, entre ellos la especie Dinheirosaurus lourinhanensis (BONAPARTE; MATEUS, 1999), macronarios basales como Lourinhasaurus alenquerensis (LAPPARENT; ZBYSZEWSKI, 1957; DANTAS; SANZ; SILVA et ál., 1998; MOCHO; ROYO-TORRES; ORTEGA et ál., 2014), muy próximo al género Camarasaurus, y un titanosauriforme basal, Lusotitan atalayensis (LAPPARENT; ZBYSZEWSKI, 1957; ANTUNES; MATEUS, 2003; MOCHO; ROYO-TORRES; ORTEGA, 2017) emparentado con los braquiosáuridos. 
Los dinosaurios terópodos del Jurásico Tardío portugués están representados por especies de tamaño medio (4-5 metros de longitud) y por grandes depredadores (hasta 10 metros) que pertenecen a grupos primitivos como Ceratosauria y Tetanurae (Megalosauridae y Allosauroidea). Los dinosaurios carnívoros de pequeño tamaño se incluyen en grupos más derivados (es decir, más modernos, evolutivamente hablando) como, por ejemplo, Coelurosauria (MALAFAIA, 2017). La asociación faunística de estos terópodos (Ceratosaurus, Allosaurus, Torvosaurus...) se ha considerado tradicionalmente como muy próxima a la documentada en la Formación Morrison de Estados Unidos y en la formación tanzana de Tendaguru (MATEUS; WALEN; ANTUNES, 2006). Sin embargo, nuevas interpretaciones han modificado este punto de vista: la presencia de taxones exclusivos de la Cuenca Lusitánica (por ejemplo Lourinhanosaurus antunesi -MATEUS, 1998- y Aviatyrannis jurassica -RAUHUT, 2003-) y la especiación de alguno de ellos (por ejemplo Allosaurus europaeus y Torvosaurus gurneyi -MATEUS; WALEN; ANTUNES, 2006; HENDRICKX; MATEUS, 2014; MALAFAIA, 2017-) permiten proponer que se produjo una separación entre la Península Ibérica y Norteamérica desde el Kimmeridgiense; esta circunstancia paleogeográfica favorecería el aislamiento de ambas masas emergidas y posibilitaría la diferenciación de nuevas especies por evolución vicariante (MALAFAIA, 2017).

Los ornitópodos del Jurásico Tardío de Portugal están representados por dos tipos de ornitópodos: una especie de pequeño tamaño de driosáurido,

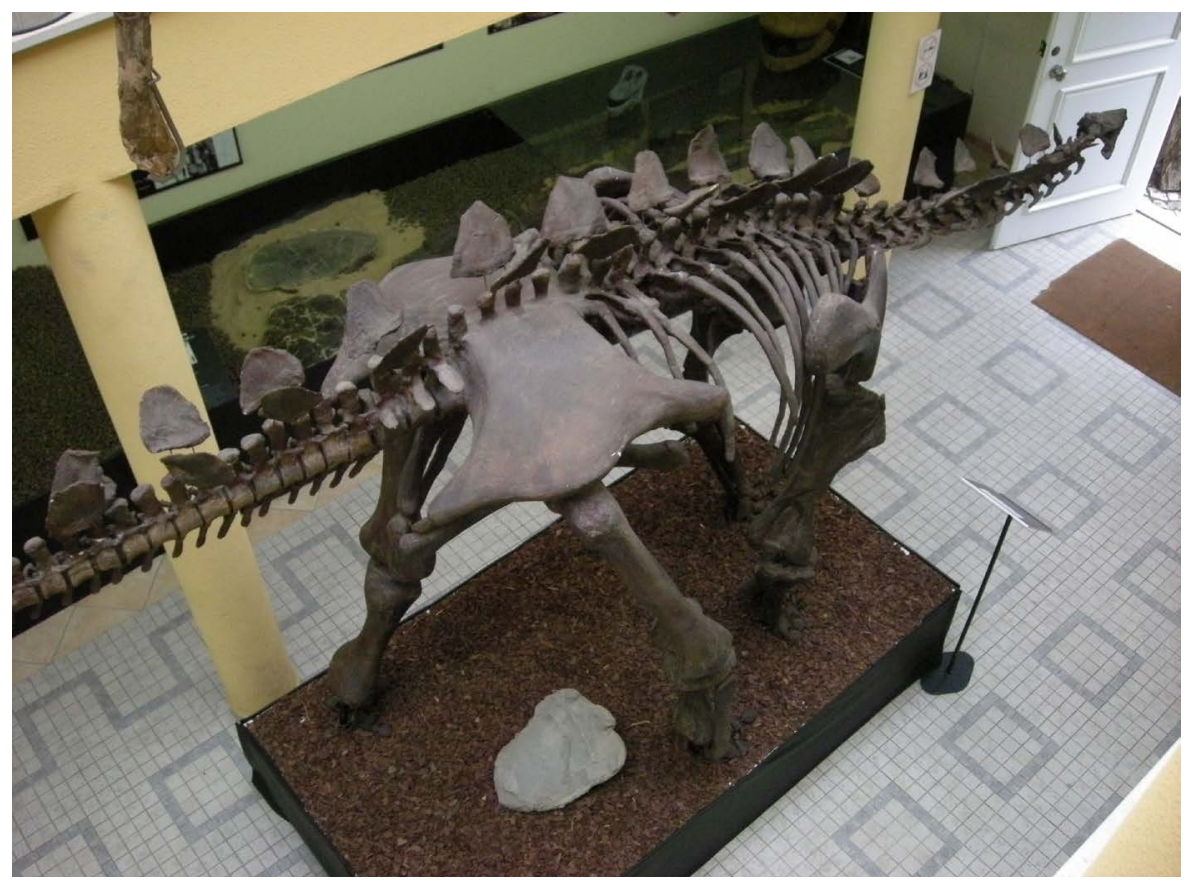


Eousdryosaurus nanohallucis (ESCASO et ál., 2014), y formas más derivadas próximas a Camptosaurus e incluidas en el clado Styracosterna. Estas últimas están representadas por Draconyx loureiroi (MATEUS; ANTUNES, 2001) y Uteodon aphanoecetes (ESCASO; ORTEGA; DANTAS, 2014). En general, el grupo de los ornitópodos es el menos abundante entre los dinosaurios del Jurásico Tardío de la Cuenca Lusitánica pero contiene formas exclusivas, como Eousdryosaurus y Draconyx, y formas con distribución a ambos lados del Atlántico, como Uteodon, descrito en la Formación Morrison de Norteamérica (McDONALD, 2011) y en la Formación Praia da AmoreiraPorto Novo de Portugal (ESCASO, 2014).

Por último, en el Jurásico Tardío de Portugal el clado Thyreophora está bien representado por dos grupos: el de los anquilosaurios, con Dracopelta zbyszewskii (GALTON, 1980; ESCASO, 2014), y el de los estegosaurios, con las especies Stegosaurus ungulatus (ESCASO, 2014) y Dacentrurus armatus. Dacentrurus es un taxón bien representado en el Jurásico Tardío de Portugal, España, Francia y Reino Unido (GALTON, 1991; COBOS et ál., 2010; ESCASO, 2014). Además, se describió una tercera especie de estegosaurio exclusiva de Portugal: Miragaia longicollum (MATEUS; MAIDMENT; CHRISTIANSEN, 2009) pero varios investigadores han justificado que el material sobre el que se sustenta este taxón corresponde a Dacentrurus (COBOS; ROYO-TORRES; LUQUE et ál., 2010; COBOS; GASCÓ, 2013; ESCASO, 2014).

El Jurásico Tardío con dinosaurios de España se encuentra principalmente en Asturias, Valencia y Teruel. La Formación Villar del Arzobispo (Kimmeridgiense-Titoniense), que aflora en las dos últimas provincias, es una de las más conocidas internacionalmente por su registro sedimentológico (CAMPOS-SOTO; BENITO; MAS et ál., 2016; CAMPOS-SOTO; COBOS; CAUS, 2017) y de nuevos taxones basados en restos directos, como el primer nuevo dinosaurio descrito de España, Aragosaurus ischiaticus (SANZ; BUSCALIONI; CASANOVAS et ál., 1987; ROYO-TORRES; UPCHURCH; MANNION et ál., 2014). Los saurisquios, representados por huesos y huellas, son los dinosaurios más abundantes. El estudio de los huesos de saurópodos ha permitido definir el clado Turiasauria que incluye a Turiasaurus riodevensis (la especie terrestre más grande descrita hasta el momento en Europa y una de las más grandes conocidas en el mundo; ROYO-TORRES; COBOS; ALCALÁ, 2006) y a Losillasaurus giganteus (CASANOVAS; SANTAFÉ; SANZ, 2001). También se encontraron en esta formación algunos restos fragmentarios atribuidos a diplodócidos y titanosauriformes (ROYO-TORRES, 2009b). Los terópodos se renonocen principalmente por fósiles de dientes aislados que pertenecen a dromeosáuridos, alosáuridos y megalosáuridos (GASCÓ; COBOS; ROYO-TORRES, 2012; COBOS, LOCKLEY; GASCÓ et ál., 2014). En cuanto a las escasas huellas dejadas por los terópodos, destaca el icnogénero Iberosauripus, con huellas 
de casi $60 \mathrm{~cm}$ de longitud (COBOS, LOCKLEY; GASCÓ et ál., 2014). Con respecto a los ornitisquios, la abundancia de huesos de estegosaurios, específicamente de Dacentrurus, y de las huellas que se le atribuyen (como es el caso del icnotaxón Deltapodus ibericus; COBOS; ROYO-TORRES; LUQUE et ál., 2010) demuestran una representación muy significativa de estos dinosaurios tireóforos durante el Jurásico Tardío de esta parte de Europa. Los huesos de los ornitópodos son menos abundantes, aunque se han descrito algunas icnitas de productores ornitópodos que indican locomoción facultativa bípeda y cuadrúpeda (PÉREZ-LORENTE; CUENCA; AURELL, 1997; CASTANERA; VILA; RAZZOLINI et ál., 2012. ALCALÁ; MAMPEL; ROYOTORRES et ál., 2014).

Los afloramientos jurásicos tardíos de gran parte de la costa asturiana presentan excelentes afloramientos en los que son abundantes los yacimientos con huellas de dinosaurios. En su mayor parte son similares a las presentes en niveles de igual edad del resto de la Península Ibérica y de Norteamérica. Los restos directos son menos abundantes pero a grandes rasgos también se han identificado asociaciones descritas en otros lugares de España y Portugal como, por ejemplo, el estegosaurio Dacentrurus, saurópodos diplodócidos y turiasaurios, entre otros (GARCÍA-RAMOS; PIÑUELA; LIRES, 2006; PIÑUELA, 2016).

En el tránsito Jurásico-Cretácico de la provincia de Soria, y especialmente en niveles datados como berriasienses, son muy abundantes las huellas de dinosaurios que a grandes rasgos también se asemejan a los icnotaxones de saurópodos, terópodos, ornitópodos y tireóforos descritos en el Jurásico
A la izquierda, excavación reciente en Las Zabacheras (Galve, Teruel), yacimiento tipo del primer nuevo dinosaurio descrito en España: Aragosaurus ischiaticus

A la derecha, afloramiento del Jurásico Tardío de la costa asturiana con restos de dinosaurios (Playa de La Griega, en Colunga, con el Museo del Jurásico de Asturias en el horizonte)
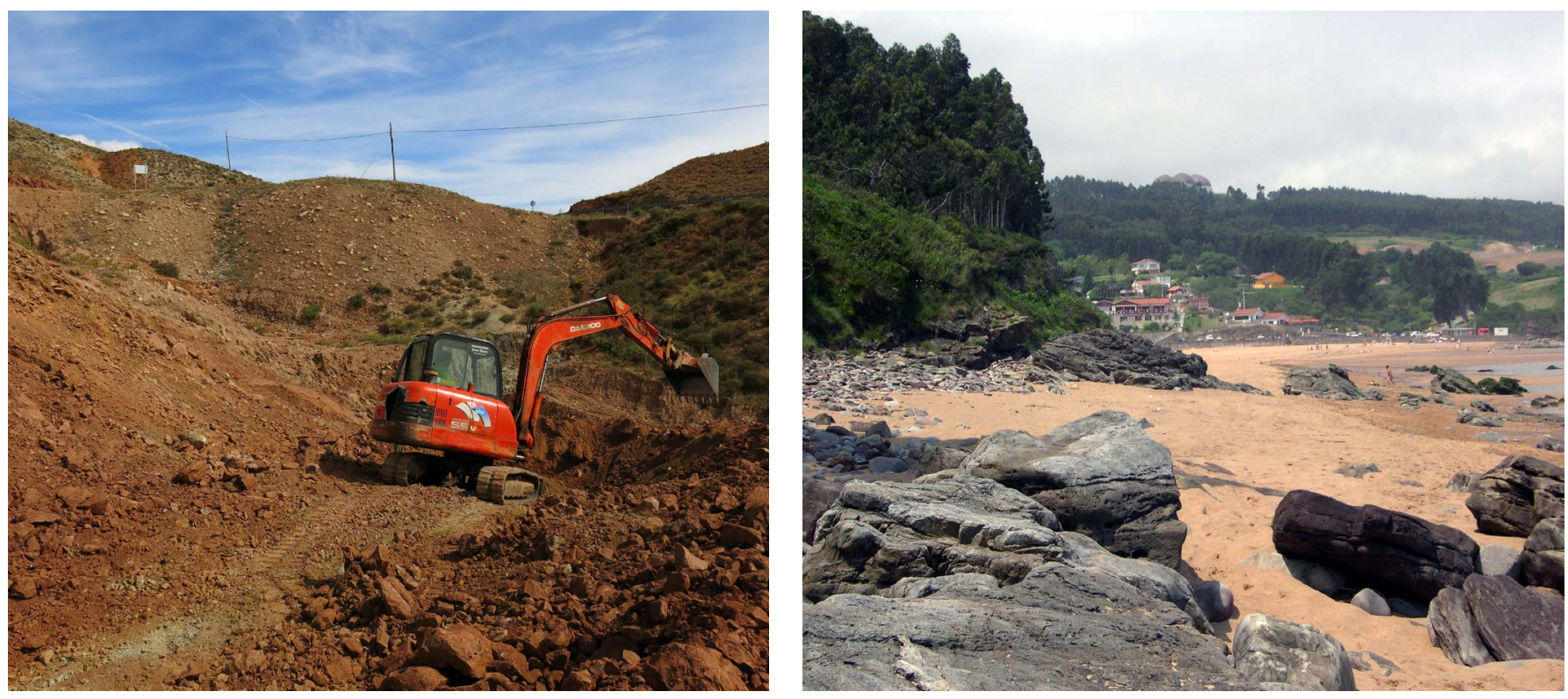
Tardío de otros lugares de la Cordillera Ibérica (PÉREZ-LORENTE, 2003; DÍAZ-MARTÍNEZ, 2013; CASTANERA; SANTOS; PIÑUELA, 2016).

En general, la fauna de dinosaurios del Kimmeridgiense-Titoniense muestra una distribución congruente con un escenario de evolución vicariante en el que la presencia de una barrera biogeográfica permitió la diferenciación de varios taxones, tanto a nivel genérico como específico, con respecto a las asociaciones de formaciones de edades semejantes (Morrison en Norteamérica y Tendaguru en Tanzania). En resumen, se constata una diferenciación en las asociaciones de los tres continentes, con la excepción de algunos taxones portugueses, como Stegosaurus y Uteodon (posiblemente relictos), similares a los de la Formación Morrison.

\section{CRETÁCICO TEMPRANO}

El Cretácico Temprano de la Península Ibérica está muy bien representado, especialmente en España (sobre todo desde el Hauteriviense hasta el Aptiense), ya que en Portugal los yacimientos de esta edad son mucho menos abundantes. Durante el Cretácico Temprano destacan las faunas barremienses y albienses de la Cordillera Ibérica. En cuanto a los saurópodos barremienses, cabe señalar especialmente a los titanosauriformes relacionados con los braquiosáuridos, como Tastavinsaurus sanzi descrito en la provincia de Teruel (CANUDO; ROYO-TORRES; CUENCA et ál., 2008; ROYOTORRES; ALCALÁ; COBOS, 2012), Europatitan eastwoodi (TORCIDA; CANUDO; HUERTA et ál., 2017), en la provincia de Burgos, y Soriatitan golmayensis de la provincia de Soria (ROYO-TORRES; FUENTES; MEIJIDE, 2017). Un segundo grupo de saurópodos presentes en estas edades son los rebaquisáuridos, representados por el taxón Demandasaurus darwini (TORCIDA; CANUDO; HUERTA et ál., 2011). Los ornitópodos dominantes eran los iguanodontios, como Magnamanus soriaensis de Soria (FUENTES; MEIJIDE; MEIJIDE-FUENTES et ál., 2016), Iguanodon galvensis de Teruel (VERDÚ; ROYO-TORRES; COBOS et ál., 2015) o Morelladon beltrani de Castellón (GASULLA; ESCASO; NARVÁEZ et ál., 2015). También en Teruel se ha definido un ornitópodo basal, Gideonmantellia amosanjuanae (RUIZOMEÑACA; CANUDO; CUENCA-BESCÓS et ál., 2012) con material de un ejemplar subadulto. Los terópodos no avianos del Barremiense más abundantes fueron alosauroideos, espinosaurios barionicinos, celurosaurios (GASULLA; ESCASO; NARVÁEZ et ál., 2006) y los ceratosaurios como Camarillasaurus cirugedae (SÁNCHEZ-HERNÁNDEZ; BENTON, 2012). Uno de los yacimientos más importantes de la Península lbérica es el de Las Hoyas en Cuenca. De allí proceden el carcarodontosaurio Concavenator corcovatus (ORTEGA; ESCASO; SANZ, 2010) y el ornitomimosaurio Pelecanimimus polyodon (PÉREZ-MORENO; SANZ; BUSCALIONI et ál., 1994), además de los terópodos avianos Iberomesornis romerali (SANZ; 


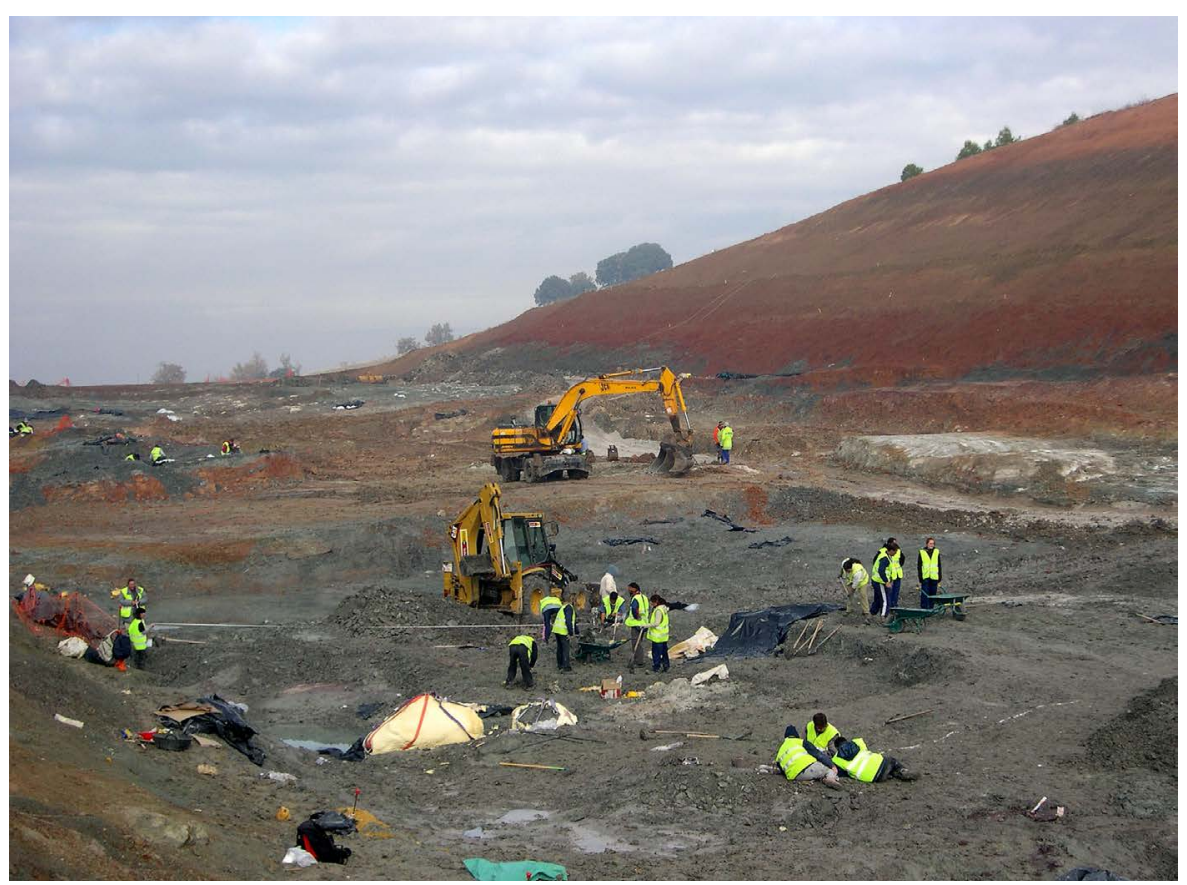

BONAPARTE; LACASA, 1988; SANZ; BONAPARTE, 1992), Concornis lacustris (SANZ; BUSCALIONI, 1992) y Eoalulavis hoyasi (SANZ; CHIAPPE; PÉREZ-MORENO et ál., 1996). Otro terópodo aviano, Noguerornis gonzalezi (LACASA-RUIZ, 1989) procede de las calizas litográficas del Barremiense del Montsec (Lérida). Entre los tireóforos, se ha identificado al anquilosaurio Polacanthus (PEREDA-SUBERBIOLA; FUENTES; MEIJIDE et ál., 2007; GASULLA; ORTEGA; PEREDA-SUBERBIOLA et ál., 2011).

Durante el Barremiense, los restos indirectos producidos por la mayor parte de los grupos mencionados anteriormente son también abundantes. Destaca, entre otros, el excelente registro fósil del yacimiento Costalomo de Burgos (HUERTA; TORCIDA; FARLOW et ál., 2012) y los centenares de huellas conservadas en forma de relleno a lo largo de múltiples capas en la Cordillera Ibérica turolense, en el denominado "Teruel Barremian Megatracksite" (COBOS; GASCÓ; ROYO-TORRES et ál., 2013; 2016).

Por lo que respecta al Aptiense, destacan la cantidad y calidad del registro icnológico de La Rioja, donde se han descrito especialmente miles de huellas terópodas, ornitópodas y saurópodas en yacimientos como El Peladillo (PÉREZ-LORENTE, 2003) y Los Cayos (MORATALLA; HERNÁN; JIMÉNEZ, 2003).

El registro de fósiles de dinosaurios del Albiense de la Península Ibérica tiene como referencia al área de las Cuencas Mineras de Teruel, en donde se defi-
Excavación del yacimiento conquense de Lo Hueco, encontrado durante las obras de trazado de la línea de ferrocarril de alta velocidad Madrid-Valencia

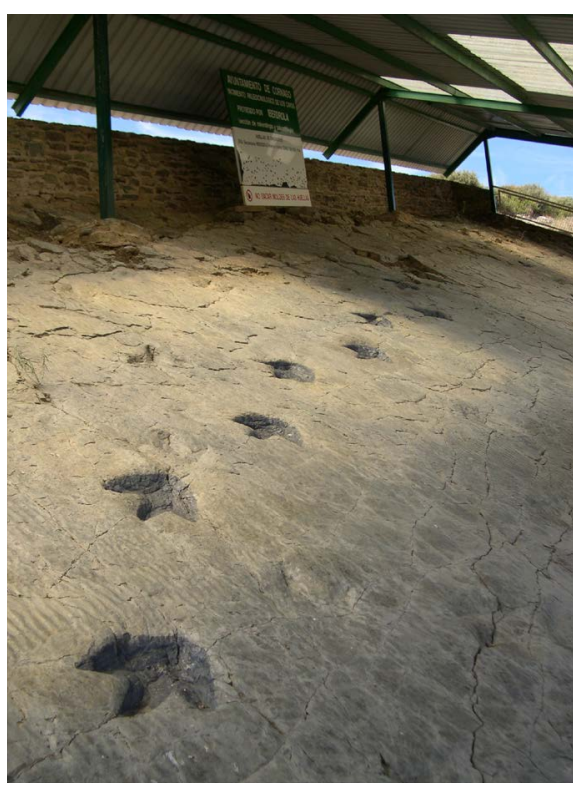

Yacimiento del Cretácico Temprano de Los Cayos en La Rioja 


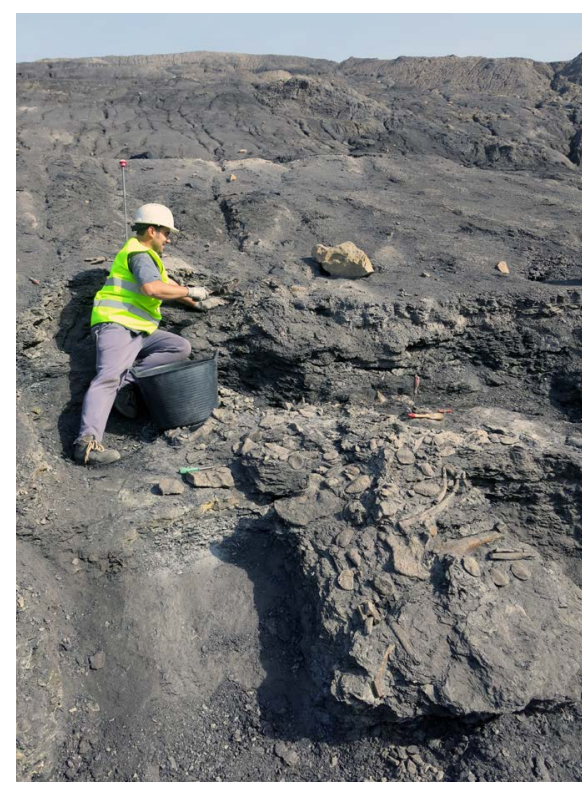

Excavación de un esqueleto parcial del nodosáurido Europelta en la Mina Santa María de Ariño (Teruel)

El megayacimiento del Albiense de Ariño (Teruel) se sitúa en el interior de la mayor mina activa de lignito española nieron las Formaciones Escucha y Utrillas. En el interior de la mina de lignito a cielo abierto Santa María de Ariño, el Albiense de la Formación Escucha presenta un extensísimo afloramiento que contiene excepcionales concentraciones de vertebrados correspondientes, por lo general, a restos de cadáveres de individuos aislados de tortugas $(35,1 \%)$, cocodrilos $(37,3 \%)$ y dinosaurios $(27,6 \%)$, aunque en algunas se encuentran restos de varios taxones (ALCALÁ; ESPÍLEZ; MAMPEL et ál., 2012; ALCALÁ; ESPÍLEZ; MAMPEL, en prensa). Hasta el momento se han descrito dos nuevos dinosaurios en Ariño, a partir de centenares de fósiles disponibles. Proa valdearinnoensis es un inusual iguanodontio basal cuyo rasgo más singular es su peculiar predentario (McDONALD; ESPÍLEZ; MAMPEL et ál., 2012). Actualmente se ha recuperado un millar de huesos tras la excavación de 27 concentraciones, lo que convierte a Proa en uno de los dinosaurios mejor representados esqueléticamente de Europa. Su análisis de parentesco lo relaciona con Iguanodon y lo sitúa en la base de los Hadrosauriformes, siendo más basal -evolutivamente hablando- que otros iguanodontios más antiguos. El conjunto de los resultados obtenidos implica una diversidad de Hadrosauriformes basales inédita en Europa (Iguanodon, Mantellisaurus, Morelladon y Proa). El segundo nuevo dinosaurio de Ariño se trata de un anquilosaurio nodosáurido: Europelta carbonensis (KIRKLAND; ALCALÁ; LOEWEN et ál., 2013), nombre que significa "el acorazado europeo del carbón". Se trata del anquilosaurio más completo hallado en Europa, pues actualmente se conocen 3.500 elementos recuperados en 18 concentraciones distintas, lo que ha permitido reconstruir de forma precisa las características anatómicas y la apariencia del animal.

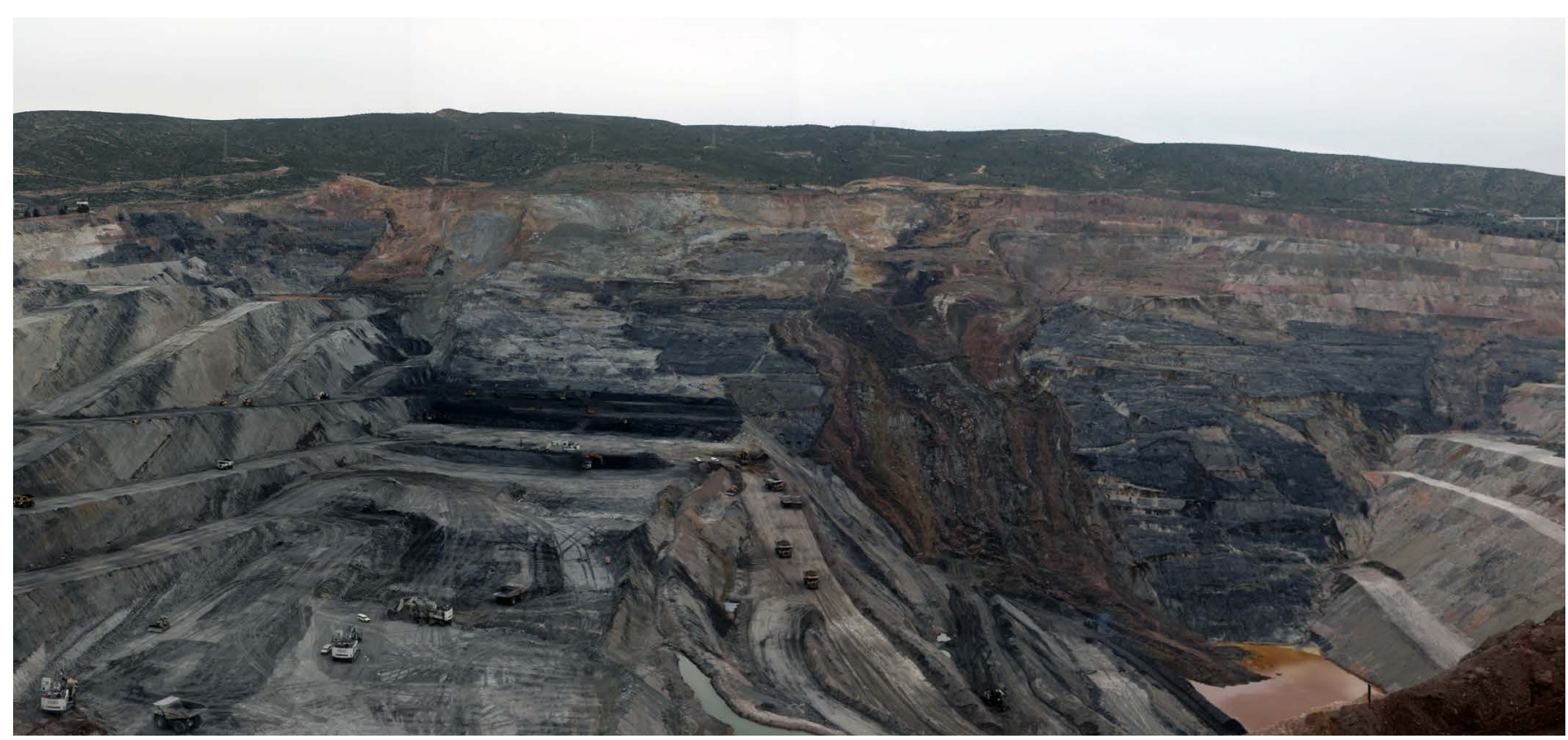




\section{CRETÁCICO TARDÍO}

En lo que respecta al Cretácico Superior, España es especialmente rica en fósiles con edades campanienses-maastrichtienses en Burgos, Huesca, Lérida, Barcelona, Cuenca y Valencia. Los saurópodos más representativos son los titanosaurios, como Lirainosaurus astibiae (SANZ; POWELL; LE LOEUFF et ál., 1999) y Lohuecotitan pandafilandi (DÍEZ DÍAZ; MOCHO; PÁRAMO et ál., 2016). A este último pertenecen decenas de ejemplares de saurópodos excepcionalmente completos que se recuperaron durante las obras realizadas para el trazado de la línea del tren de alta velocidad de Madrid a Valencia, en el importante yacimiento conquense denominado Lo Hueco (ORTEGA; SANZ; BARROSO-BARCENILLA et ál., 2008). Entre los ornitópodos del Cretácico Superior se han definido cuatro hadrosaurios en el sector pirenaico español: Arenysaurus ardevoli (PEREDA-SUBERBIOLA; CANUDO; CRUZADO-CABALLERO et ál., 2009), Blasisaurus canudoi (CRUZADO-CABALLERO; PEREDA-SUBERBIOLA; RUIZ-OMEÑACA, 2010), Koutalisaurus kohlerorum (PRIETO-MÁRQUEZ; GAETE; RIVAS et ál., 2006) y Pararhabdodon isonensis (CASANOVAS-CLADELLAS; SANTAFÉ-LLOPIS; ISIDORO-LLORÉNS, 2003). Respecto a los tireóforos, se han citado Struthiosaurus en diferentes localidades españolas y manirraptores entre los terópodos.

También se han identificado huellas atribuidas a los grupos de dinosaurios previamente citados en diferentes yacimientos ibéricos. Destacan sobremanera los afloramientos del Maastrichiense del sur de los Pirineos, como en el megayacimiento Fumanya (SCHULP; BROKX, 1999; VILA; OMS; GALOBART, 2005), con cientos de huellas saurópodas atribuidas a titanosaurios y otras ornitópodas de hadrosáuridos. Además, las mismas facies son especialmente ricas en huevos de dinosaurios (VILA; RIERA; BRAVO et ál., 2011).

\section{LA UTILIZACIÓN COMO RECURSO GEOTURÍSTICO Y EDUCATIVO}

Los dinosaurios y los ecosistemas mesozoicos de los que formaron parte son uno de los máximos atractivos de la paleontología para la sociedad actual. Desde que en 1854 se inauguró en Inglaterra la primera gran exposición sobre vertebrados del pasado, la atracción mediática de los dinosaurios en diferentes lugares del mundo queda reflejada en las instalaciones promovidas en innumerables yacimientos, localidades o regiones ricas en este tipo de fósiles, bien sea a través de rutas temáticas, museos de sitio o exomuseos, museos de paleontología o de historia natural, parques paleontológicos, etc. En muchos casos, el objetivo principal de la intervención en estos lugares trasciende a la mera conservación de los yacimientos y persigue también la llegada de visitantes que dinamicen socioeconómicamente 
el entorno más próximo a los mismos o a los centros museísticos (COBOS, 2011). En este sentido, tiene un papel especialmente relevante el caso de las icnitas de dinosaurios por los motivos que se detallan a continuación.

$>$ Complementan la información que aportan los huesos de dinosaurios. Así mientras los huesos de dinosaurios constituyen un registro inerte que sirven para descifrar "quiénes eran", sus icnitas muestran a los dinosaurios como seres vivos, al informar, además, acerca de "qué estaban haciendo y dónde lo hacían", dejando impresa la evidencia de su actividad en los sedimentos que el tiempo y los procesos geológicos han convertido en mensajes paleontológicos perdurables. Estos documentos, especialmente bien representados entre el Jurásico Medio y el Cretácico Tardío de Portugal y España (Aragón, Asturias, Castilla y León, Cataluña, La Rioja y Valencia, principalmente), sirven para reconstruir una historia singular: el registro fósil de los dinosaurios que caminaron en un momento y en un lugar de características cambiantes, con la apertura del entonces inexistente Océano Atlántico como rasgo más significativo.

$>$ A través de las huellas se puede determinar el grupo de dinosaurios productores $\mathrm{y}$, por lo tanto, la sucesión de las faunas de estos vertebrados a lo largo del Mesozoico. Pero, además, las huellas aportan una información paleobiológica y paleoecológica que no se puede determinar a través del estudio de los huesos. Desde el punto de vista paleobiológico, las icnitas aportan muchos datos sobre la vida pretérita:

a) una huella individualizada proporciona información sobre el autor de la misma: grupo taxonómico, anatomía autopodial (de manos y pies), tamaño del dinosaurio productor, etc.;

b) un rastro aporta, además, datos sobre la constitución anatómica del dinosaurio responsable: características de las extremidades, velocidad de desplazamiento, posibles patologías, etc.;

c) una asociación de rastros transmite conocimientos sobre el comportamiento del grupo: orientación preferencial, gregarismo, etc.

> Desde el punto de vista paleoecológico ( $y$ a diferencia de los huesos que pudieron sufrir transporte antes, durante y después de la fosilización), las huellas fósiles quedan registradas en rocas formadas en un ecosistema determinado; por eso, tras la interpretación sedimentológica del sustrato en el que se disponen las huellas, se puede reconocer el ambiente concreto en el que vivieron los dinosaurios que las produjeron hace millones de años. Además a través de las huellas se establecen censos faunísticos, orientaciones preferenciales de la marcha de los dinosaurios y otras informaciones complementarias muy útiles en las reconstrucciones paleogeográficas. 


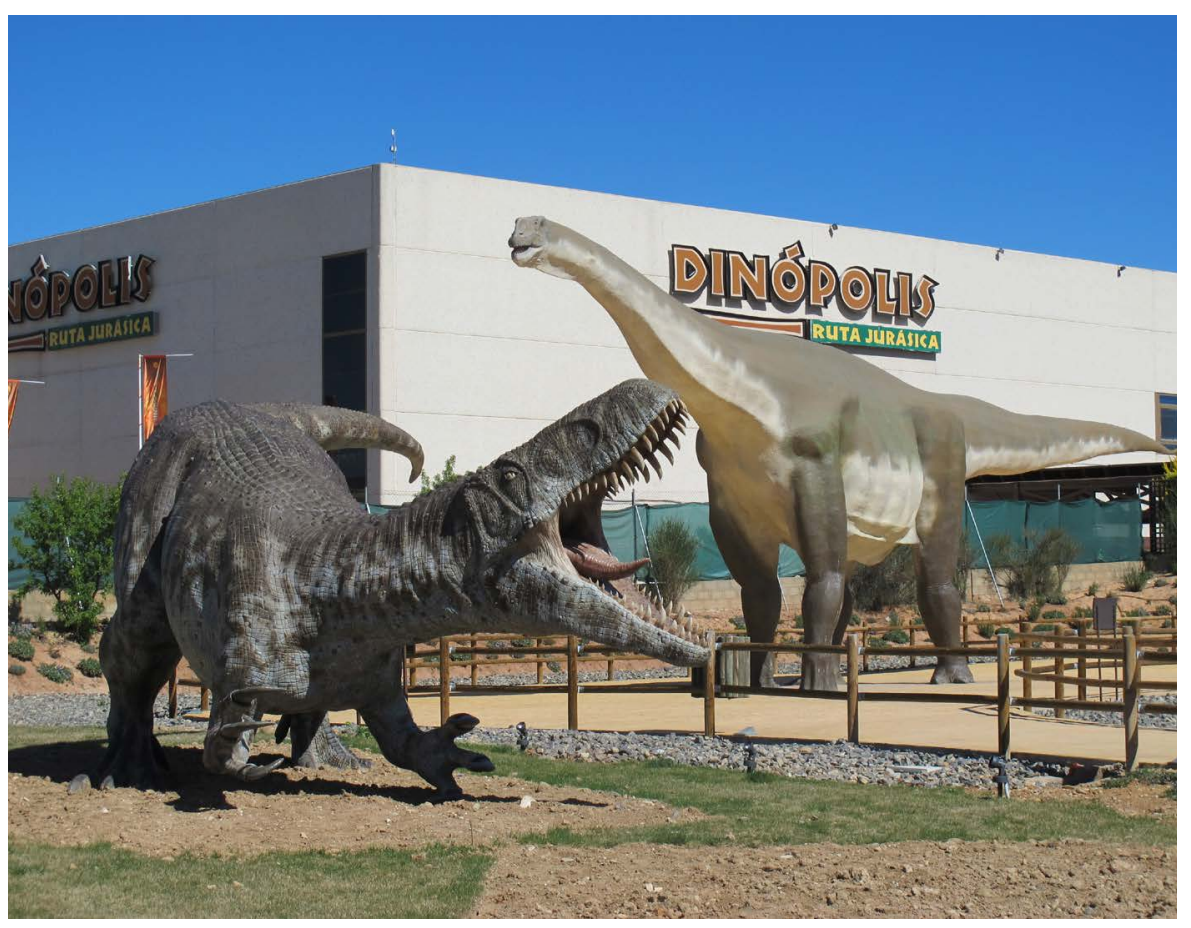

$>$ Pero, fundamentalmente, y teniendo en cuenta que tanto huesos como huellas de dinosaurios son cruciales para descifrar la evolución y el comportamiento de los dinosaurios, las icnitas se encuentran normalmente expuestas al aire libre en afloramientos geológicos, por lo que:

a) necesitan medidas excepcionales de conservación si se quiere evitar su deterioro por la acción de agentes naturales o antrópicos (mientras que, al contrario, los huesos se suelen conservar adecuadamente en los museos), y

b) sirven para promover el desarrollo local en áreas rurales, pues se necesita un desplazamiento hasta los propios yacimientos para conocerlas y disfrutar de ellas.

Toda la riqueza dinosauriológica de la Península Ibérica mostrada anteriormente a grandes rasgos conduce a que se desarrollen proyectos de diversa índole y escala relacionados con la investigación, conservación y difusión de sus recursos paleontológicos. Generalmente, afectan a las zonas en las que se encuentran los yacimientos de dinosaurios y, en algunos casos, generan un verdadero impulso socioeconómico en zonas demográficamente deprimidas. Así, se han excavado, adecuado y habilitado yacimientos de dinosaurios en zonas que destacan por poseer este recurso natural y se han creado centros paleontológicos de diversa envergadura en localidades relacionadas con sus fósiles. Algunos de ellos destacan en Aragón, como el Parque

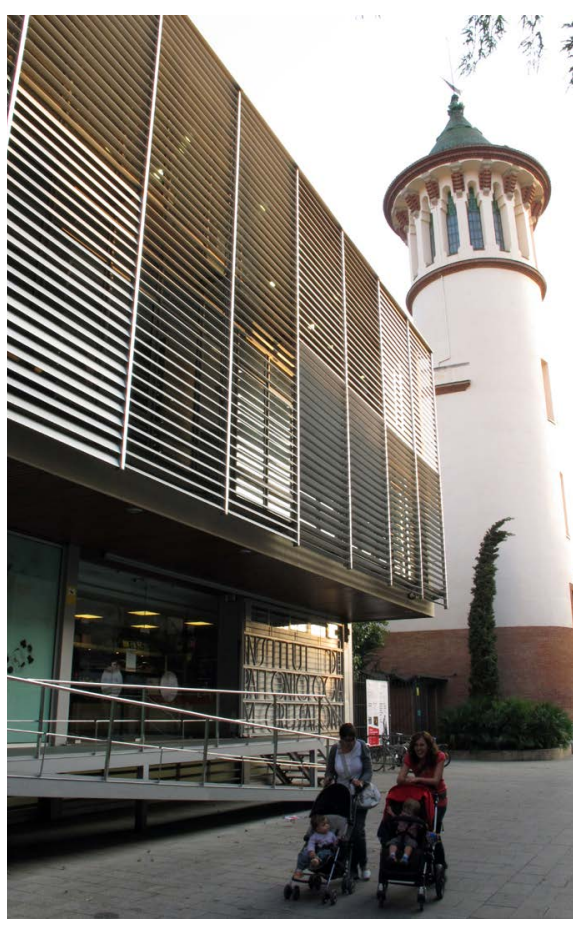

A la izquierda, instalaciones de Dinópolis en Teruel con la reconstrucción de su dinosaurio más emblemático, Turiasaurus (el gigante europeo), al fondo

A la derecha, museo del Institut Català de Paleontologia M. Crusafont en Sabadell (Barcelona) 
Paleontológico Dinópolis en la provincia de Teruel o el Museo de los Últimos Dinosaurios de Europa de Arén (Huesca). En Cataluña, el Museu de la Conca Dellà y espacio Dinosfera (Lérida), entre otros. En el Principado de Asturias se encuentra el Museo del Jurásico de Asturias, en Castilla y León el Museo de Dinosaurios de Salas de los Infantes (Burgos) y el Aula Paleontológica de Villar del Río (Soria). En La Rioja, los centros paleontológicos de Enciso e Igea, en la Comunidad Valenciana, el Aula y Museo Paleontológico de Alpuente (Valencia) y Temps de Dinosaures en Morella (Castellón) o, en Castilla-La Mancha, el Museo de Paleontología de Castilla-La Mancha. Además, también se deben tener en cuenta los museos paleontológicos de larga tradición, como el Museo Nacional de Ciencias Naturales (CSIC) en Madrid y el Institut Català de Paleontologia M. Crusafont en Barcelona, entre otros. En Portugal destaca el Museu da Lourinhã, y la intervención en el yacimiento de icnitas de Pedreira do Galinha, una antigua cantera de caliza (COBOS, 2011; SANTOS; COBOS; ALCALÁ, 2011).

\section{LA GESTIÓN PATRIMONIAL DEL PATRIMONIO DINOSAURIOLÓGICO IBÉRICO}

El patrimonio de los dinosaurios ibéricos se gestiona conforme a las regulaciones y tradiciones de cada uno de los países, con una casuística tan variada (colecciones públicas o privadas, museos y/o centros de investigación, legislación específica o genérica, etc.) como habitual en países que se interesan por el inventario y conservación de su patrimonio científico y cultural (CARCAVILLA; LÓPEZ; DURÁN, 2007; BRILHA; ALCALÁ; ALMEIDA et ál., 2010). Sin embargo, cabe señalar una iniciativa poco común que ha desembocado en el establecimiento de las máximas figuras de protección en cada uno de los dos Estados para un tipo de fósiles directamente relacionado con el patrimonio dinosauriológico: las icnitas de dinosaurios. La gran diversidad de tipos de huellas, su abundancia, el prolongado periodo de tiempo geológico que abarcan (un centenar de millones de años), la relación con numerosos yacimientos de restos directos contemporáneos y su comparación con otras áreas geográficas de dimensiones semejantes (teniendo en cuenta características de sus entornos geológicos y paleontológicos) convierten a la Península Ibérica en una de las áreas de mayor interés para el estudio del comportamiento, evolución y dispersión de los dinosaurios de todo el planeta. De ahí que el Ministerio de Cultura de España y el Ministerio do Ambiente, do Ordenamento do Territorio e do Desenvolvimiento Regional (de Portugal) decidieran, hace algunos años, impulsar una candidatura para la inclusión de los yacimientos de dinosaurios de la Península Ibérica en la Lista de Patrimonio Mundial de la UNESCO.

La primera consecuencia de dicha iniciativa conllevó que muchos yacimientos ibéricos de icnitas compartan la característica de poseer las máxi- 
mas figuras de protección previstas en la legislación de cada país. Esto se debe no tanto a una concienciación de las administraciones o de las sociedades respectivas acerca de la conveniencia de su protección tanto legal como efectiva (lo que habría demostrado una madurez que se habría hecho extensiva hacia otro tipo de yacimientos paleontológicos) sino a un lógico requisito ligado a la propia candidatura: para conseguir la inclusión de ciertos bienes en una lista supranacional, la UNESCO espera que tales bienes hayan sido merecedores previamente de la máxima protección nacional en los países solicitantes. En un primer momento la candidatura solo incluía yacimientos españoles, a pesar de presentarse bajo la denominación Icnitas de Dinosaurios de la Península Ibérica (IDPI), y el gran número y diversidad de huellas se presentaba como su principal fortaleza. En una decisión tomada en la 30a sesión del World Heritage Committee, celebrada en 2006 en Lituania (Decision 30 COM 8B.26), se recomendó al Estado español la subsanación de los siguientes aspectos con objeto de justificar el posible valor universal excepcional del bien propuesto:

$>$ el establecimiento de un marco conceptual que demuestre la relación de los yacimientos españoles con otros portugueses de importancia;

> la comparación con el yacimiento Cal Orck'o de Bolivia (objeto de una ayuda preparatoria en aquel momento por parte de World Heritage Fund);

$>$ la realización de un cuidadoso análisis comparativo global (incluyendo la justificación de los motivos por los cuales una propiedad basada en icnitas de dinosaurios puede considerarse merecedora de un Valor Universal Excepcional, VUE);

$>$ y, finalmente, la presentación de una nominación seriada coherente y manejable, enfocada a un número mucho menor de localidades y todas ellas con relevancia global.

En los años siguientes se trabajó para satisfacer los requisitos demandados mediante la redacción de una nueva candidatura con las características que se resumen a continuación (FCPTD, 2009; ALCALÁ, 2012).

$>$ Presentación de un marco conceptual que no sólo relacionaba los yacimientos españoles con los portugueses, sino que incluía formalmente al Estado portugués en una nueva candidatura transnacional seriada. Dicho esquema conceptual, bajo el lema DWDW (Dinosaurs Walking in a Drifting World) estableció tres intervalos espacio-temporales en los que se registra la evolución de los dinosaurios en la Placa Ibérica durante momentos de la disgregación de masas emergidas. Simultáneamente, se establecieron criterios para reducir considerablemente el número de yacimientos propuestos en la candidatura, de los 216 españoles iniciales a únicamente 3 yacimien- 
Los once yacimientos de icnitas de dinosaurios ibéricos seleccionados para ilustrar la sucesión espacio-temporal del registro de dinosaurios en la Península | fuente FCPTD, 2009 (IDPI); mapa geológico: IGME

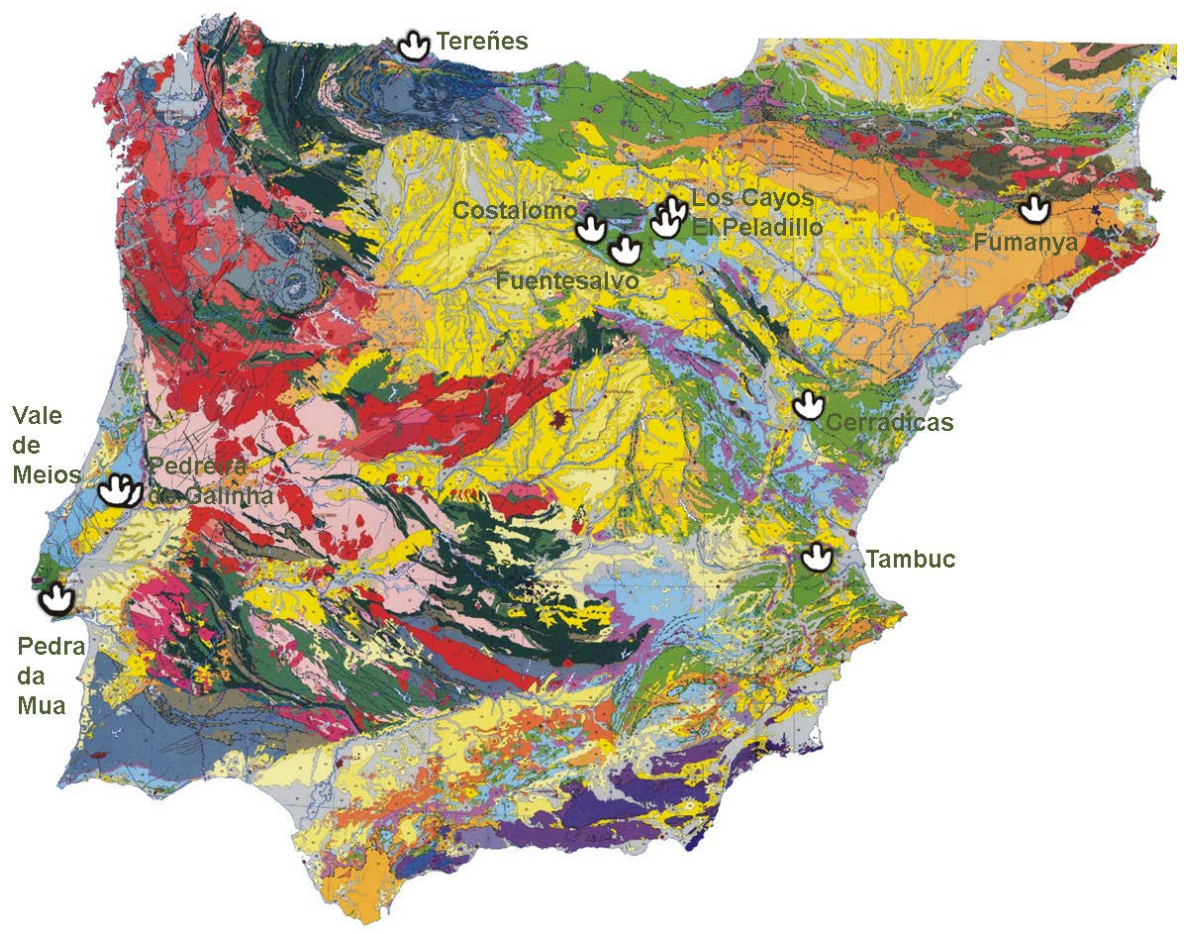

tos de Portugal y 8 de España. Para ello, se otorgaron valores numéricos a 11 categorías relacionadas con su valor científico para cada uno de los 230 yacimientos españoles y portugueses analizados (metodología explicada en MAMPEL; COBOS; ALCALÁ et ál., 2009 y ALCALÁ; LOCKLEY; COBOS et ál., 2016). El nuevo marco conceptual se presenta, de modo resumido, en los siguientes párrafos.

Las huellas de dinosaurios de la Península Ibérica pueden encuadrarse en diferentes dominios o lugares geológico/geográficos que ayudan a comprender los eventos geológicos que llevaron a configurar entornos ecológicos determinados en los que vivieron las diferentes asociaciones faunísticas de dinosaurios. Todo ello hace del IDPI un megalaboratorio para avanzar en el conocimiento de la distribución de las faunas de dinosaurios, en relación con sus nichos ecológicos, en Pangea y en el oeste de Laurasia. Además, se pueden establecer los múltiples modos de vida y comportamientos de los dinosaurios.

En el caso de las huellas de dinosaurios de la Península Ibérica se reconocen tres áreas muy representativas tanto de los ambientes donde se formaron los yacimientos como de las distintas épocas en las que vivieron. Estas áreas tienen un contexto geológico propio dentro de la tectónica de placas que afectó a lberia durante parte del Mesozoico: 
1. La Costa de los Dinosaurios, representada por yacimientos del Jurásico Medio y Tardío de Portugal y del noroeste de España, formados durante la expansión del Proto-Atlántico.

Del análisis general de las huellas y huesos descritos en los afloramientos jurásicos de la Península Ibérica se establece que durante esa época abundaban los grandes saurópodos, como los eusaurópodos, diplodócidos y titanosauriformes basales. Generalmente, sus huellas se relacionan con otras de terópodos de diferentes tallas: carnosaurios, espinosáuridos, ceratosáuridos y manirraptores. Entre los tireóforos destacan los estegosaurios y anquilosaurios.

Esta asociación de fósiles de dinosaurios, reflejada en la Península Ibérica, reproduce perfectamente a los diferentes grupos de dinosaurios presentes

Esquema del marco conceptual que sintetiza la evolución de los dinosaurios en la Placa Ibérica desde el Jurásico Medio hasta su extinción | fuente FCPTD, 2009 (IDPI)

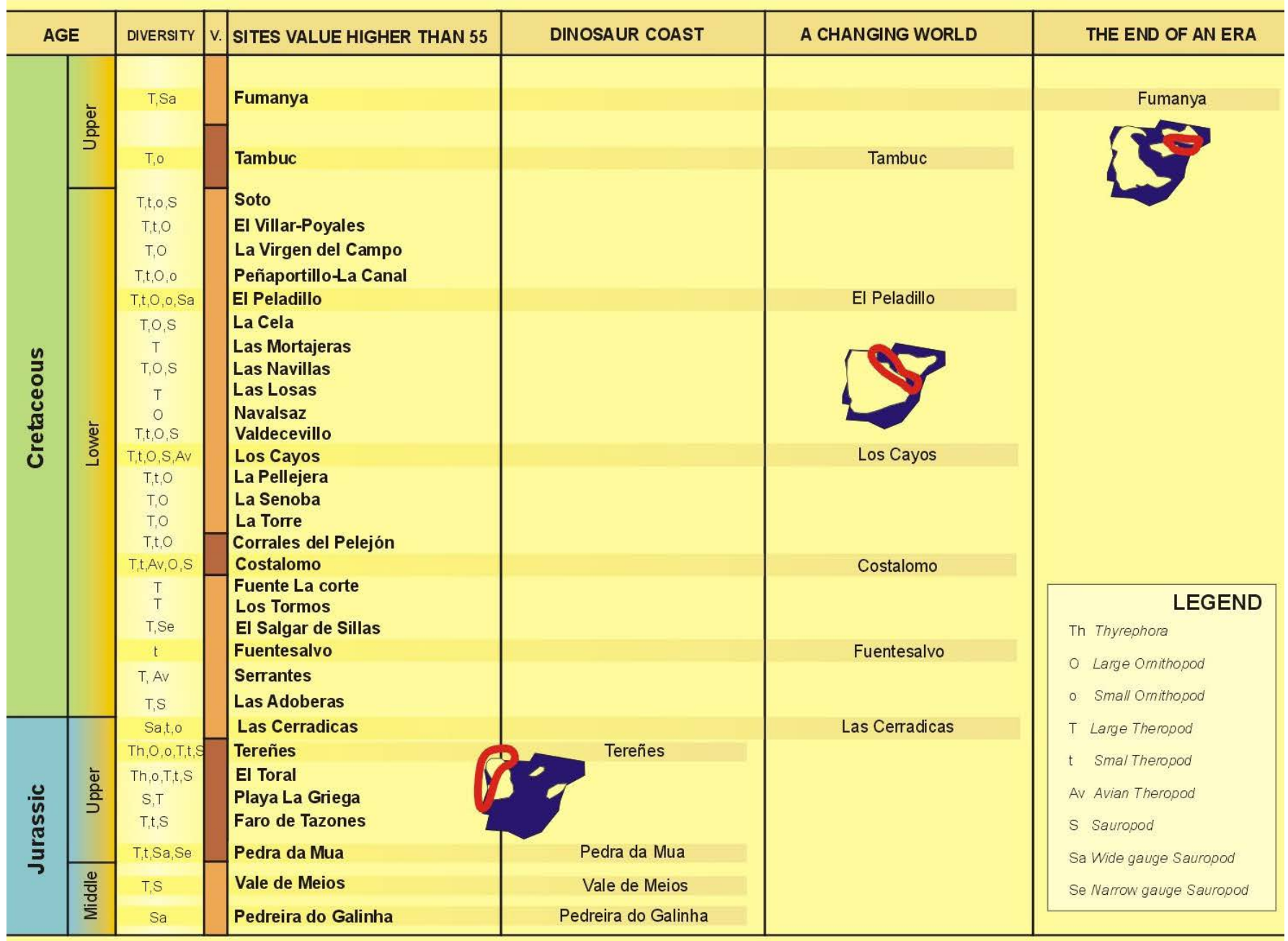


en el Jurásico Medio-Tardío a nivel mundial. Para representar este dominio geológico se seleccionaron los siguientes yacimientos (tras la valoración patrimonial científica correspondiente):

$>$ En el Jurásico Medio, Pedreira do Galinha, Santarém, con rastros anchos de saurópodos; y Vale de Meios, Santarém, con miles de huellas terópodas grandes de carnosaurios y algún rastro de saurópodo.

$>$ En el Jurásico Superior, Pedra de Mua, Setubal, con varios rastros anchos y estrechos de saurópodos y algún terópodo grande; Tereñes, Asturias, con ornitópodos, terópodos, saurópodos y estegosáuridos.

2. Un Mundo Cambiante, representado por yacimientos originados en el llamado Estrecho o Surco de Soria, en periodos que abarcan desde el límite Jurásico-Cretácico, pasando por diferentes edades del Cretácico Temprano, hasta parte del Cretácico Tardío de España.

En este dominio los restos directos e indirectos muestran el cambio de faunas producido entre las faunas típicas del Jurásico Tardío (abundancia de saurópodos) y las faunas del Cretácico Temprano (abundancia de ornitópodos).

En el Cretácico Temprano prosiguen las faunas de saurópodos titanosauriformes y, en menor medida, los diplodócidos, como los rebaquisáuridos. Paulatinamente se pasa de ornitópodos basales, como camptosáuridos y driosáuridos, al predominio de iguanodontios e hipsilofodóntidos.

Si se consideran sólo los restos indirectos, indican que las huellas terópodas son las dominantes, si bien los restos directos muestran lo contrario. Este desequilibrio entre huesos y huellas se ha intentado relacionar con la favorable fosilización -o no- de unos restos respecto a otros en diferentes ecosistemas. Los tireóforos, aunque presentes, estarían limitados a áreas muy restringidas.

Este dominio geológico, y por lo tanto de la Península Ibérica, es uno de los mejores lugares del mundo donde, en pocos kilómetros, se puede constatar claramente a través de las icnitas el cambio de faunas de dinosaurios que se produjo a nivel mundial entre el Jurásico y el Cretácico.

Una vez valorados metodológicamente los yacimientos del dominio, se consideró que los más representativos desde el punto de vista científico, tanto por su edad como por lo que representan respecto a la sucesión faunística de los dinosaurios, eran:

> En el tránsito Jurásico-Cretácico (Titoniense-Berriasiense), Las Cerradicas, Teruel, con rastros de ornitópodos cuadrúpedos pequeños y con rastros 
anchos de pequeños saurópodos, principalmente; Fuentesalvo, Soria, con múltiples rastros de icnitas tridáctilas terópodas.

$>$ En el Cretácico Temprano (Hauteriviense-Barremiense), Costalomo, Burgos, con huellas de terópodos pequeños y grandes, terópodos avianos, ornitópodos cuadrúpedos grandes y saurópodos.

$>$ En el Cretácico Temprano (Aptiense), El Peladillo, La Rioja, con miles de huellas: terópodas grandes y pequeñas, ornitópodas grandes y pequeñas y saurópodas; Los Cayos, La Rioja, con huellas terópodas grandes y pequeñas, avianas y ornitópodas.

$>$ En el Cretácico Tardío (Santoniense-Campaniense), Tambuc, Valencia, con huellas medianas de terópodo/ornitópodo.

3. El Final de una Era es el dominio de los yacimientos que se concentran en el Pirineo español. Estos yacimientos se formaron en las cuencas mesozoicas presentes durante el cierre de la unión entre el Océano Atlántico y el Mar de Tethys, al inicio de la Orogenia Alpina.

Durante el Cretácico Tardío, la representación de los saurópodos se limita a la presencia de titanosáuridos y, entre los ornitópodos, a la abundancia

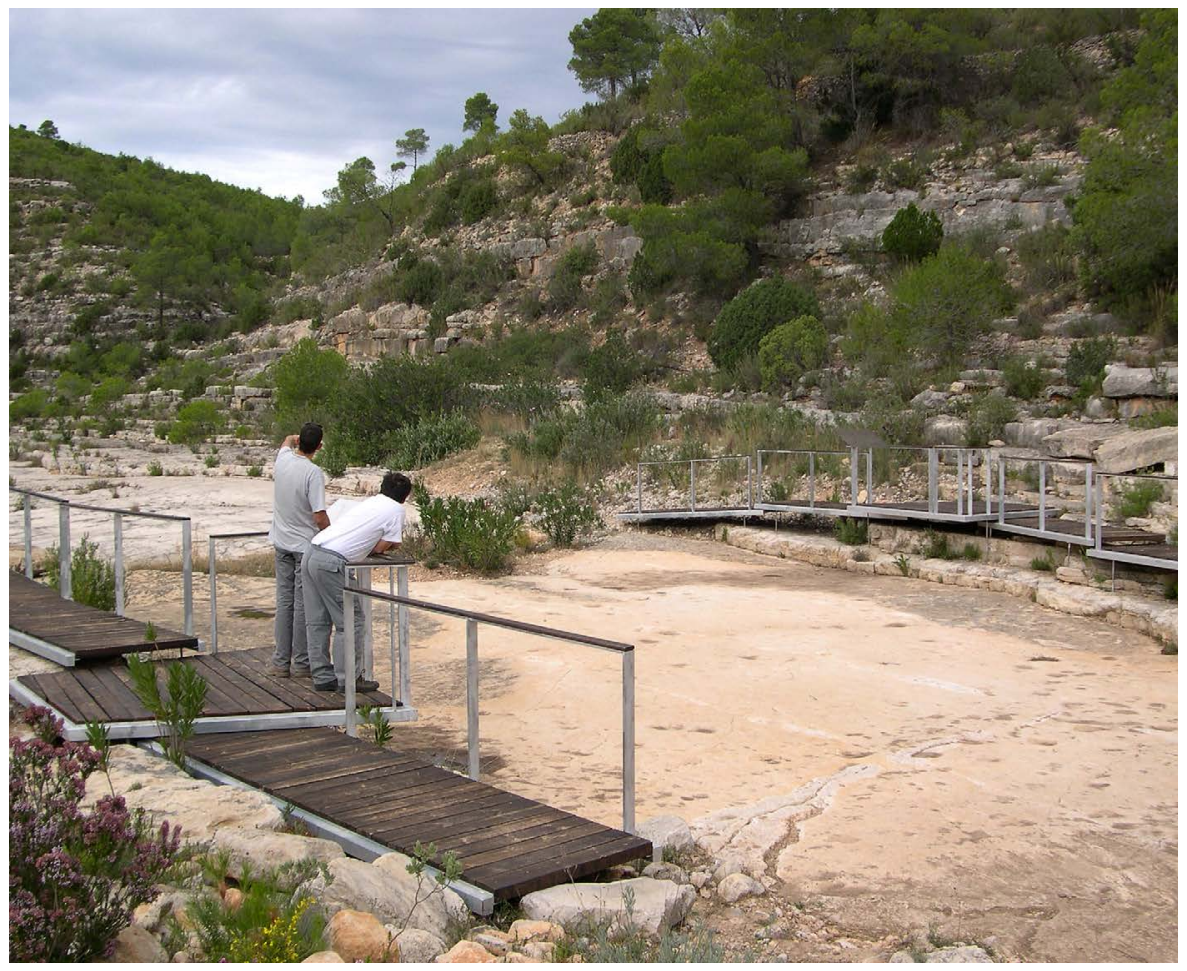


de hadrosáuridos. Entre los terópodos, predominaron los de talla media y pequeña. Tanto los restos directos como los indirectos indican que en esta parte de Laurasia los ceratópsidos no existieron o bien no dejaron evidencias reconocibles hasta el momento en el registro fósil.

Una vez valorados metodológicamente los yacimientos de este dominio, se consideró que el más representativo era:

$>$ En el Cretácico Superior (Maastrichtiense), Fumanya, Barcelona, con miles de huellas saurópodas de rastro ancho y algunas huellas terópodas grandes.

Con una candidatura contextualizada y un número de yacimientos manejable y con una notable representatividad, se procedió a la comparación específica de los yacimientos ibéricos con el boliviano y se desarrolló un sistema de comparación con los principales yacimientos de icnitas de dinosaurios de todo el mundo. Con tal propósito se estableció una comparación entre zonas (bajo el concepto de "geositio") y no entre yacimientos individuales, según la recomendación del grupo de trabajo IUGS (International Union of Geological Sciences) GEOSITES y ProGEO en el sentido de que "en vez de considerar candidaturas aisladas... sería recomendable recopilar listas de entidades geológicas similares y que estos listados se utilicen como marco comparativo para extraer candidatos a la Lista de Patrimonio Mundial".

La nueva candidatura se evaluó en la $34^{a}$ sesión del World Heritage Committee, celebrada en 2010 en Brasil, con unos antecedentes pesimistas, pues la evaluación técnica previa de la IUCN (International Union for Conservation of Nature), tras la visita realizada por dos expertos comisionados por UNESCO en 2009, fue la de rechazar la inscripción del bien en la Lista de Patrimonio Mundial, por considerar que no había sido posible establecer el Valor Universal Excepcional (VUE) de una nominación enfocada únicamente en los valores de las icnitas de dinosaurios. Afortunadamente, la defensa pública de la candidatura por parte de la delegación hispano-portuguesa en dicha sesión consiguió el éxito de modificar tal propuesta por la de un aplazamiento (Decision 34 COM 8B.7) para permitir a los Estados solicitantes el desarrollo de un análisis comparativo global que incluyese la justificación de un Valor Universal Excepcional para una propiedad basada en icnitas de dinosaurios, así como consideraciones acerca de una nominación seriada con propiedades ya existentes. Por lo tanto, se había conseguido presentar una candidatura coherente pero que necesitaba encontrar un argumento que satisficiera el concepto que los evaluadores tenían acerca del VUE. Dada la dificultad para descifrar la interpretación de tal concepto, se programó una reunión a puerta cerrada, a instancias del Ministerio de Cultura de España, de cuatro expertos del máximo nivel internacional (un paleontólogo especialista en icnitas de dinosaurios, un geólogo especialista en patrimonio geológico, un geólogo con altas responsabilidades en un órgano asesor 


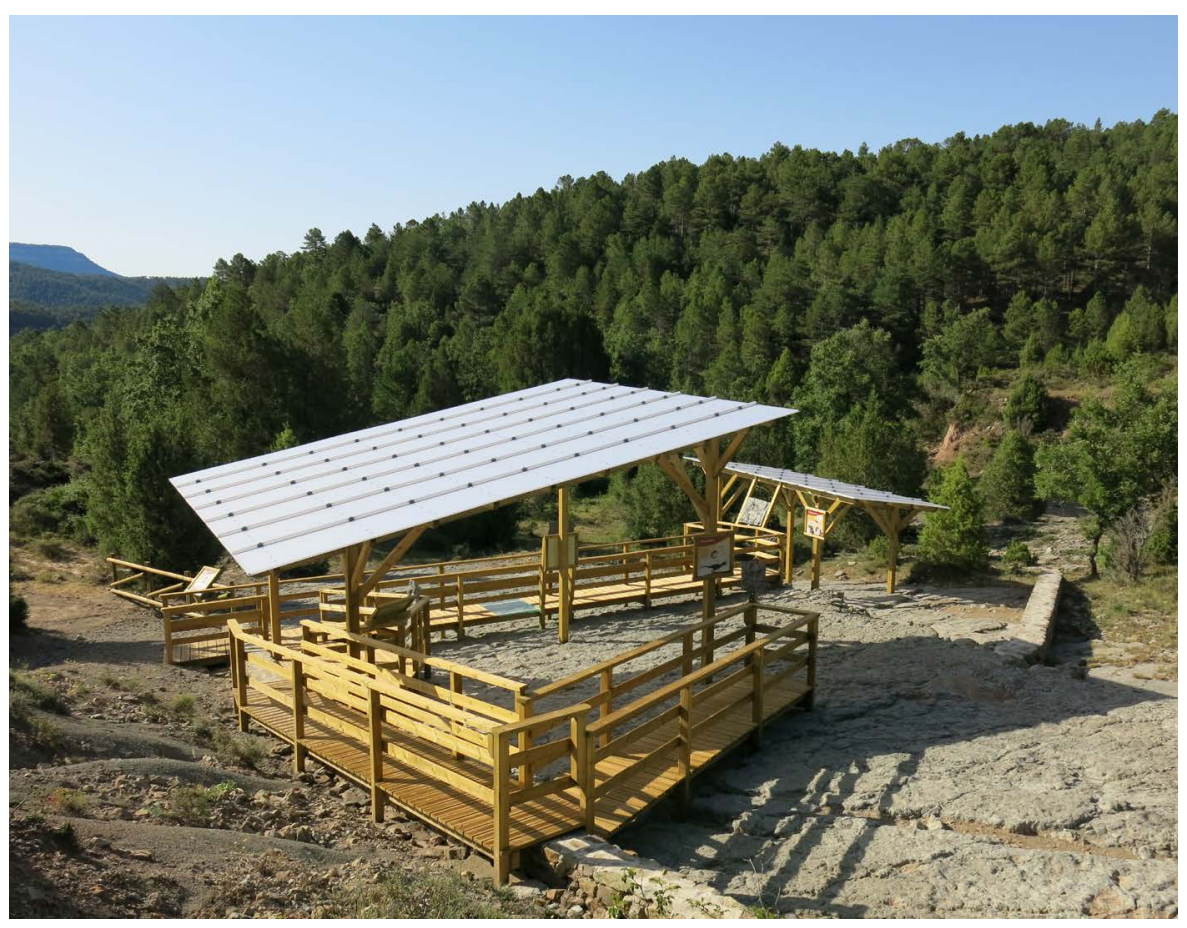

de UNESCO y un geólogo experto en evaluaciones de candidaturas de bienes para su inclusión en la Lista de Patrimonio Mundial y en geoparques) con el coordinador científico de la candidatura IDPI para determinar el modo de responder a la justificación del VUE de una candidatura de icnitas de dinosaurios. La reunión, con el título International Scientific Experts Meeting: The Outstanding Universal Value of the Dinosaurs Ichnites with regard to the World Heritage List, se celebró en mayo de 2011 en Teruel y se obtuvieron fructíferas conclusiones acerca de cómo enfocar una respuesta convincente a la decisión del Comité de Patrimonio Mundial. Sin embargo, los resultados no llegaron a aplicarse pues, tras los cambios de representantes en las Comunidades Autónomas españolas y en las administraciones de los Estados de España y Portugal con motivo de las elecciones que tuvieron lugar por aquellas fechas, la candidatura cayó en un olvido que culminó con la decisión de abandonar el proyecto y eliminar de la Lista Indicativa española de Patrimonio Mundial la propuesta de la candidatura (acuerdo tomado en la reunión del Consejo de Patrimonio Histórico celebrada en Córdoba el año 2016). Por su parte, Portugal también retiró a partir de 2016 el bien Icnitos de Dinossáurios da Península Ibérica de su Lista Indicativa.

No obstante lo anterior, todo el proceso descrito ha dejado una notable impronta en la nutrida lista de yacimientos legalmente protegidos y en la ingente documentación que se recopiló de cada uno de ellos, así como en las numerosas actuaciones de conservación, investigación y difusión que se
Yacimiento de icnitas recientemente habilitado en El Castellar (Teruel), una localidad muy poco poblada pero en la que se demuestra un interés creciente en promover el geoturismo 
llevaron a cabo y que merecería la pena continuar de un modo coordinado como una marca de calidad natural de geoturismo ibérico. Así lo han considerado oportuno ciertas áreas ibéricas que apuestan todavía por un geoturismo fundamentado en sus recursos dinosauriológicos locales.

\section{CONCLUSIONES}

La Península Ibérica cuenta con un registro muy representativo de la evolución de los dinosaurios desde el Jurásico Medio hasta el Cretácico terminal. La gran diversidad de tipos de dinosaurios que comprende, su abundancia y el prolongado intervalo temporal que abarca -100 millones de años- permite proponer que, tras su comparación con el registro dinosauriológico de otras áreas geográficas de dimensiones semejantes ( $\mathrm{y}$ teniendo en cuenta no sólo características de los propios yacimientos sino también de su entorno geológico), se pueda considerar como una de las áreas de mayor interés de nuestro planeta para el estudio de los dinosaurios.

\section{Agradecimientos}

Agradecemos al Dr. Bienvenido Martínez-Navarro, coordinador de este número monográfico, su invitación a participar en el mismo. Nuestra contribución se inscribe en los proyectos de la Fundación Conjunto Paleontológico de Teruel-Dinópolis apoyados por el Departamento de Educación, Cultura y Deporte del Gobierno de Aragón, el Ministerio de Economía y Competitividad y Fondo Social Europeo (proyecto DINOTUR CGL2013-41295-P), FOCONTUR (Grupo de investigación de referencia E04_17R, Departamento de Innovación, Investigación y Universidad, Gobierno de Aragón y Fondo Social Europeo) y el Instituto Aragonés de Fomento. 


\section{BIBLIOGRAFÍA}

- AGUIRREZABALA, L. M.; VIERA, L. I. (1980) Icnitas de dinosaurios en Bretún (Soria). Munibe, 32, 1980, pp. 3-4

- ALCALÁ, L. (2012) The IDPI (Icnitas de Dinosaurios de la Península Ibérica) WHL candidacy in perspective. En HUH, M.; KIM, H. J.; PARK, J. Y. (ed.) The 11th Symposium on Mesozoic Terrestrial Ecosystems. Gwanju, Korea: Chonnam National University, 2012, pp. 255-258

- ALCALÁ, L.; ESPÍLEZ, E.; MAMPEL, L.; KIRKLAND, J. I.; ORTIGA, M.; RUBIO, D.; GONZÁLEZ, A.; AYALA, D.; COBOS, A.; ROYO-TORRES, R.; GASCÓ, F. (2012) New Lower Cretaceous vertebrate bonebed in Ariño (Teruel, Aragón, Spain) found and managed by joint collaboration between a mining company and a palaeontological park. Geoheritage, 4 (4), 2012, pp. 275-286

- ALCALÁ, L.; MAMPEL, L.; ROYO-TORRES, R.; COBOS, A. (2014) On small quadrupedal ornithopod tracks in Jurassic-Cretaceous transition intertidal deposits (EI Castellar, Teruel, Spain). Spanish Journal of Paleontology, 29 (2), 2014, pp. 183-190

- ALCALÁ, L.; LOCKLEY, M. G.; COBOS, A.; MAMPEL, L.; ROYO-TORRES, R. (2016) Evaluating the Dinosaur Track record: an integrative approach to understanding the regional and global distribution, scientific importance, preservation and management of tracksites. En FALKINGHAM, P. L.; MARTY, D.; RICHTER, A. (ed.) Dinosaur Tracks, The Next Steps. Bloomington, IN: Indiana University Press, 2016, pp. 100-116

- ALCALÁ, L.; ESPÍleZ, E.; MAMPEL, L. (en prensa) Ariño: la mina de los dinosaurios. En XIII Jornadas de Paleontología Aragonesa. Zaragoza: Institución Fernando el Católico, en prensa

- ANDRÉS, J. A.; ALCALÁ, I.; BARCO, J. L.; CANUDO, J. I.; COBOS, A.; GARCÍA-PIMIENTA, J. C. (2007) Un paseo con los dinosaurios por Aragón (Yacimientos de icnitas de dinosaurio). Zaragoza: Consejo de Protección de la Naturaleza, 2007

- ANTUNES, M. T.; MATEUS, O. (2003) Dinosaurs of Portugal. Comptes Rendus Palevol, 2, 2003, pp. 77-95

- BARCO, J. L. (2009) Sistemática e implicaciones filogenéticas y paleobiogeográficas del saurópodo Galvesaurus herreroi (Formación Villar del Arzobispo, Galve, España). Tesis doctoral inédita, Universidad de Zaragoza, 2009

- BONAPARTE, J. F.; MATEUS, O. (1999) A new diplodocid, Dinheirosaurus lourinhanensis gen et sp. nov., from the Late Jurassic beds of Portugal. Revista del Museo Argentino de Ciencias Naturales, 5, 1999, 13-29

- BRILHA, J.; ALCALÁ, L.; ALMEIDA, A.; ARAÚJO, A.; AZEVEDO, A.; AZEVEDO, M. R.; BARRIGA, F.; BRUM DA SILVEIRA, A.; CABRAL, J.; CACHÃO, M.; CAETANO, P.;
COBOS, A.; COKE, C.; COUTO, H.; CRISPIM, J.; CUNHA, P. P.; DIAS, R.; DUARTE, L.V.; DÓRIA, A.; FALÉ, P.; FERREIRA, N.; FERREIRA SOARES, A.; FONSECA, P.; GALOPIM DE CARVALHO, A.; GONÇALVES, R.; GRANJA, H.; HENRIQUES, M. H.; KULLBERG, J.C.; KULLBERG, M. C.; LEGOINHA, P.; LIMA, A.; LIMA, E.; LOPES, L.; MADEIRA, J.; MARQUES, J. F.; MARTINS, A.; MARTINS, R.; MATOS, J.; MEDINA, J.; MIRANDA, R.; MONTEIRO, C.; MOREIRA, M.; MOURA, D.; NETO DE CARVALHO, C.; NORONHA, F.; NUNES, J. C.; OLIVEIRA, J. T.; PAIS, J.; PENA DOS REIS, R.; PEREIRA, D.; PEREIRA, P.; PEREIRA, Z.; PIÇARRA, J.; PIMENTEL, N.; PINTO DE JESUS, A.; PRADAS, S.; PREGO, A.; RAMALHO, L.; RAMALHO, M.; RAMALHO, R.; RELVAS, J.; RIBEIRO, A.; RIBEIRO, M.A.; ROCHA, R.; SÁ, A.; SANTOS, V. F.; SANT'OVAIA, H.; SEQUEIRA, A.; SOUSA, M.; TERRINHA, P.; VALLE AGUADO, B.; VAZ, N. (2010) O inventário nacional do património geológico: abordagem metodológica e resultados. E-Terra [en línea], 18 (1), 2010, pp. 1-4 <https://repositorium.sdum.uminho. pt/bitstream/1822/45668/1/2010_eTerra_JBrilha.pdf> [Consulta: 26/03/2018]

- CAMPOS-SOTO, S.; BENITO, M. I.; MAS, R.; CAUS, E.; COBOS, A.; SUAREZ-GONZALEZ, P.; QUIJADA, I. E. (2016) Revisiting the Late Jurassic-Early Cretaceous of the NW South Iberian Basin: new ages and sedimentary environments. Journal of Iberian Geology, 42, 2016, pp. 6994

- CAMPOS-SOTO, S.; COBOS, A.; CAUS, E.; BENITO, M. I.; FERNÁNDEZ-LABRADOR, L. SUAREZ-GONZALEZ, P.; QUIJADA, I. E.; MAS R.; ROYO-TORRES, R.; ALCALÁ, L. (2017) Jurassic Coastal Park: A great diversity of palaeoenvironments for the dinosaurs of the Villar del Arzobispo Formation (Teruel, eastern Spain). Palaeogeography, Palaeoclimatology, Palaeoecology, 485, 2017, pp. 154-177

- CANUDO, J. I.; ROYO-TORRES, R.; CUENCABESCÓS, G. (2008) A new sauropod: Tastavinsaurus sanzi gen. et sp. nov. from the Early Cretaceous (Aptian) of Spain. Journal of Vertebrate Paleontology, 28 (3), 2008, pp. 712-731

- CARCAVILLA URQUÍ, L.; LÓPEZ MARTÍNEZ, J.; DURÁN VALSERO, J. J. (2007) Patrimonio geológico y geodiversidad: investigación, conservación, gestión y relación con los espacios naturales protegidos. Instituto Geológico y Minero de España. Cuadernos del Museo Geominero, 7, 2007, pp. 1-405

- CASANOVAS-CLADELLAS, M. L.; SANTAFÉ-LLOPIS, J. V.; ISIDORO-LLORENS, A. (1993) Pararhabdodon isonense n. gen. n. sp. (Dinosauria). Morphology, radiotomographic study, and biomechanic considerations. Paleontologia i Evolució, 26-27, 1993, pp. 21-131

- casanovas, M. L.; SANTAFÉ, J. V.; SANZ, J. L. (2001) Losillasaurus giganteus, un nuevo saurópodo del 
tránsito Jurásico-Cretácico de la cuenca de «Los Serranos» (Valencia, España). Paleontologia i Evolució, 32-33, 2001, pp. 99-122

- CASTANERA, D. (2013) Aspectos paleoecológicos a partir del registro icnológico de tetrápodos en el intervalo Jurásico-Cretácico de la Cordillera Ibérica (Cameros oriental y Maestrazgo). Tesis doctoral inédita, Universidad de Zaragoza, 2013

- CASTANERA, D.; VILA, B.; RAZZOLINI, N. L.; FALKING HAM, P. L.; CANUDO, J. I.; MANNING, P. L.; GALOBART, A. (2013) Manus track preservation bias as a key factor for assessing trackmarker identity and quadrupedalism in basal ornithopods. PLOS ONE [en línea] 8(1): e54177. <https://doi.org/10.1371/journal.pone.0054177> [Consulta: 26/03/2018]

- CASTANERA, D.; SANTOS, V. F.; PIÑUELA, L.; PASCUAL, C.; VILA, B.; CANUDO, J. I.; MORATALLA, J. (2016) Iberian sauropod tracks throught time: Variations in sauropod manus and pes track morphologies, En FALKINGHAM, P. L.; MARTY, D.; RICHTER, A. (ed.) Dinosaur Tracks, the Next Steps. Bloomington, IN: Indiana University Press, 2016, pp. 120-137

- cobos, A. (2011) Los dinosaurios de Teruel como recurso para el desarrollo territorial. Tesis doctoral inédita. Universidad del País Vasco, 2011

- COBOS, A.; ROYO-TORRES, R.; LUQUE, L.; ALCALÁ, L.; MAMPEL, L. (2010) An Iberian stegosaurs paradise: The Villar del Arzobispo Formation (Tithonian-Berriasian) in Teruel (Spain). Palaeogeography, Palaeoclimatology, Palaeoecology, 293, 2010, pp. 223-236

- coBos, A.; GASCÓ, F. (2013) New vertebral remains of the stegosaurian dinosaur Dacentrurus from Riodeva (Teruel, Spain). Geogaceta, 53, 2013, pp. 17-20

- COBOS,A.; GASCÓ, F.; ROYO-TORRES, R.;ALCALÁ, L. (2013) "Dinoichnofacies" barremienses en Teruel (España). En ÁLVAREZ-VÁZQUEZ, C.; LÓPEZ RODRÍGUEZ, I. (ed.) Libro de Resúmenes de las XXIX Jornadas de la Sociedad Española de Paleontología. Córdoba: Real Jardín Botánico de Córdoba, 2013, pp. 65-66

- COBOS, A.; LOCKLEY, M. G.; GASCÓ, F.; ROYOTORRES, R.; ALCALÁ, L. (2014) Megatheropods as apex predators in the typically Jurassic ecosystems of the Villar del Arzobispo Formation (Iberian Range, Spain). Palaeogeography, Palaeoclimatology, Palaeoecology, 399, 2014, pp. 31-41

- COBOS, A.; GASCÓ, F.; ROYO-TORRES, R.; LOCKLEY, M. G.; ALCALÁ, L. (2016) Dinosaur tracks as "four-dimensional phenomena" reveal how different species moved. En FALKINGHAM, P. L.; MARTY, D.; RICHTER, A. (ed.) Dinosaur Tracks, the Next Steps. Bloomington, IN: Indiana University Press, 2016, pp. 244-254
- COMPANY, J. (2004) Vertebrados continentales del Cretácico Superior (Campaniense-Maastrichtiense) de Valencia. Tesis doctoral inédita, Universidad de Valencia, 2004

- CRuZAdO-CABAllero, P. (2012) Restos directos de dinosaurios hadrosáuridos (Ornithopoda, Hadrosauridae) del Maastrichtiense superior (Cretácico Superior) de Arén (Huesca). Tesis doctoral inédita, Universidad de Zaragoza, 2012

- CRUZADO-CABALLERO, P.; PEREDA-SUBERBIOLA, X.; RUIZ-OMEÑACA, J. I. (2010) Blasisaurus canudoi gen. et sp. nov., a new lambeosaurine dinosaur (Hadrosauridae) from the Latest Cretaceous of Arén (Huesca, Spain). Canadian Journal of Earth Sciences, 47 (12), 2010, pp. 1507-1517

- CUESTA, E. (2017) Concavenator corcovatus (Theropoda, Dinosauria) from Las Hoyas fossil site (Early Cretaceous, Cuenca, Spain): Taphonomic, phylogenetic and morphofunctional analyses. Tesis doctoral inédita, Universidad Autónoma de Madrid, 2017

- DANTAS, P.; SANZ, J. L.; SILVA, C. M.; ORTEGA, F.; SANTOS, V. F.; CACHAO, M. (1998) Lourinhasaurus n.gen. novo dinossáurio saurópode do Jurássico superior (Kimmeridgiano superior-Titoniano inferior) de Portugal. En Actas do V Congresso de Geologia, 84. Lisboa: Instituto Geológico e Mineiro, Ministério da Economia, 1998, pp. A91-A94

- DÍAZ-MARTÍNEZ, I. (2013) Icnitas de dinosaurios bípedos de La Rioja (Cuenca de Cameros, Cretácico Inferior): Icnotaxonomía y aplicación paleobiológica. Tesis doctoral inédita, Universidad de La Rioja, 2013

- DÍEZ DÍAZ, V. (2013) Revisión del dinosaurio saurópodo Lirainosaurus astibiae (Titanosauria) del Cretácico Superior de la Península Ibérica: comparación con otros titanosaurios del suroeste de Europa, Hipótesis filogenética y paleobiogeográfica. Tesis doctoral inédita, Universidad del País Vasco, 2013

- DÍEZ dÍAZ, V.; MOCHO, P.; PÁRAMO, A.; ESCASO, F.; MARCOS-FERNÁNDEZ, F.; SANZ, J. L.; ORTEGA, F. (2016) A new titanosaur (Dinosauria, Sauropoda) from the Upper Cretaceous of Lo Hueco (Cuenca, Spain). Cretaceous Research, 68, 2016, pp. 49-60

- ESCASO, F. (2014) Historia evolutiva de los Ornithischia (Dinosauria) del Jurásico Superior de Portugal. Tesis doctoral inédita, Universidad Autónoma de Madrid, 2014

- ESCASO, F.; ORTEGA, F.; DANTAS, P.; MALAFAIA, E.; SILVA, B.; GASULLA, J. M.; MOCHO, P.; NARVÁEZ, I.; SANZ, J. L. (2014) A new dryosaurid ornithopod (Dinosauria, Ornithischia) from the Late Jurassic of Portugal. Journal of Vertebrate Paleontology, 34 (5), 2014, pp. 1102-1112 
- FCPTD (Fundación Conjunto Paleontológico de TeruelDinópolis) (coord.) (2009) Dinosaur Ichnites of the Iberian Peninsula. World Heritage Candidacy. Ministerio de Cultura de España and Ministerio do Ambiente, do Ordenamento do Territorio e do Desenvolvimiento Regional, Portugal. Memoria inédita

- FUENTES, C.; MEIJIDE CALVO, M.; MEIJIDEFUENTES, F.; MEIJIDE-FUENTES, M. (2016) Un nuevo dinosaurio estiracosterno (Ornithopoda: Ankylopollesia) del Cretácico Inferior de España. Spanish Journal of Palaeontology, 31 (2), 2016, pp. 407-446

- GALTON, P. M. (1980) Partial skeleton of Dracopelta zbyszewskii n. gen. and n. sp., an ankylosaurian dinosaur from the Upper Jurassic of Portugal. Geobios, 13 (3), 1980, pp. $451-457$

- GaltoN, P. M. (1991) Postcranial remains of stegosaurian dinosaur Dacentrurus from Upper Jurassic of France and Portugal. Geologica et Paleontologica, 25, 1991, pp. 299-327

- GARCÍA-ORTíz DE LANDALUCE, E. (2016) Análisis de los yacimientos de icnitas de La Rioja ( $N$ de España) como recurso patrimonial y aplicación de nuevas tecnologías a su estudio. Tesis doctoral, inédita, Universidad de León, 2016

- GARCÍA-RAMOS, J. C.; PIÑUELA, L.; LIRES, J. (2006) Atlas del Jurásico de Asturias. Oviedo: Ediciones Nobel,2006

- GASCA, J. M. (2015) Aportaciones al conocimiento sobre los dinosaurios del Barremiense inferior (Cretácico Inferior) de Teruel, España: asociaciones fósiles, sistemática, paleobiodiversidad y afinidades paleobiogeográficas. Tesis doctoral inédita. Universidad de Zaragoza, 2015

- GASCÓ, F. (2015) Anatomía funcional de Turiasaurus riodevensis (Dinosauria, Sauropoda). Tesis doctoral inédita. Universidad Autónoma de Madrid, 2015

- GASCÓ, F.; COBOS, A.; ROYO-TORRES, R.; MAMPEL, L.; ALCALÁ. L. (2012) Theropod teeth diversity from the Villar del Arzobiso Formation (Tithonian-Berriasian) at Riodeva (Teruel, Spain). Palaeobiodiversity and Palaeoenvironments, 92 (2), 2012, pp. 273-286

- GASUlLA, J. M. (2015) Los dinosaurios de la Cantera del Mas de la Parreta, Morella (Formación Morella, Barremiense superior, Cretácico Inferior): Sistemática, análisis filogenético e implicaciones paleobiológicas. Tesis doctoral inédita, Universidad Autónoma de Madrid, 2015

- GASULLA, J. M.; ORTEGA, F.; ESCASO, F.; SANZ, J. L. (2006) Diversidad de terópodos del Cretácico Inferior (Fm Arcillas de Morella, Aptiense) en los yacimientos del Mas de la Parreta (Morella, Castellón). En FERNÁNDEZMARTíNEZ, E. (ed.) Libro de resúmenes. XXII Jornadas de la Sociedad Española de Paleontología (León, 27-30 de Septiembre del 2006). León: Universidad, Secretariado de Publicaciones , 2006, pp. 124-125

- GASULLA, J. M.; ORTEGA, F.; PEREDA-SUBERBIOLA, X.; ESCASO, F.; SANZ, J. L. (2011) Elementos de la armadura dérmica del dinosaurio anquilosaurio Polacanthus Owen, 1865, en el Cretácico Inferior de Morella (Castellón, España). Ameghiniana, 48 (4), 2011, pp. 508-519

- GASUlLA, J. M.; ESCASO, F.; ORTEGA, F.; SANZ, J. L. (2014) New hadrosauriform cranial remains from the Arcillas de Morella Formation (lower Aptian) of Morella, Spain. Cretaceous Research, 47, 2014, pp. 19-24

- GASULLA, J. M.; ESCASO, F.; NARVÁEZ, I.; ORTEGA, F.; SANZ, J. L. (2015) A new Sail-Backed Styracosternan (Dinosauria: Ornithopoda) from the Early Cretaceous of Morella, Spain. Plos ONE [en línea], 10 (12), 2015 <http:// journals. plos.org/plosone/article?id=10.1371/journal. pone.0144167> [Consulta: 30/04/2018]

- GOMES, J. P. (1916) Descoverta de rastos de saurios gigantescos no Jurássico do Cabo Mondego. Comunicações Comissão Serviços Geológicos de Portugal, 11, 1916, pp. 132-134

- HENDRICKX, C; ; MATEUS, O. (2014) Torvosaurus gurneyi n. sp., the Largest Terrestrial Predator from Europe, and a Proposed Terminology of the Maxilla Anatomy in Nonavian Theropods. Plos ONE[en línea], 9(3), 2014, <http:// journals. plos.org/plosone/article?id=10.1371/journal. pone.0088905> [Consulta: 30/04/2018]

- HUERTA, P.; TORCIDA FERNÁNDEZ-BALDOR, F.; FARLOW, J. O.; MONTERO, D. (2012) Exceptional preservation processes of $3 \mathrm{D}$ dinosaur footprint casts in Costalomo (Lower Cretaceous, Cameros Basin, Spain). Terra Nova, 24, 2012, pp. 136-141

- KIRKLAND, J. I.; ALCALÁ, L.; LOEWEN, M.; ESPÍLEZ, E.; MAMPEL, L.; WIERSMA, J. (2013) The Basal Nodosaurid Ankylosaur Europelta carbonensis n. gen., n. sp. from the Lower Cretaceous (Lower Albian) Escucha Formation of NortheasternSpain.PLoSONE[enlínea],8(12), 2013,<http:// journals. plos.org/plosone/article?id=10.1371/journal. pone.0080405> [Consulta: 30/04/2018]

- LACASA-RUIZ, A. (1989) New genus of fossil bird from the Neocomian locality of Montsec (Lerida province, Spain). Estudios geológicos, 45 (5-6), 1989, pp. 417-425

- LAPPARENT, A. F.; ZBYSZEWSKI, G. (1957) LeS dinosauriens du Portugal. Memórias dos Serviços Geológicos de Portugal, 2, 1957, pp. 1-63

- LOCKLEY, M. G.; MEYER, C. A.; SANTOS, V. F. (1994) Trackway evidence for a herd of juvenile sauropods from the Late Jurassic of Portugal. Gaia: Revista de Geociencias, Museu Nacional de Historia Natural (Lisbon), 10, 1994, pp. 
27-36

- MAlafAiA, E. (2017) Phylogenetic analysis, paleoenvi ronmental and paleobiogeographic interpretation of thero pod dinosaurs from the Upper Jurassic of the Lusitanian Basin. Tesis doctoral inédita, Universidad de Lisboa, 2017

- MAlafAiA, E.; ORTEGA, F.; ESCASO, F.; SILVA, B. (2015) New evidence of Ceratosaurus (Dinosauria: Theropoda) from the Late Jurassic of the Lusitanian Basin, Portugal. Historical Biology, 27 (7), 2015, pp. 938-946

- MAlAFAiA, E.; MOCHO, P.; ESCASO, F.; ORTEGA, F. (2017) New data on the anatomy of Torvosaurus and other remains of megalosauroid (Dinosauria, Theropoda) from the Upper Jurassic of Portugal. Journal of Iberian Geology, 43, pp. 33-59

- MAMPEL, L.; COBOS, A.; ALCALÁ, L.; LUQUE, L.; ROYO-TORRES R. (2009) An Integrated System of Heritage Management Applied to Dinosaur Sites in Teruel (Aragón, Spain). Geoheritage, 1 (2-4), 2009, pp. 53-73

- MATEUS, O. (1998) Lourinhanosaurus antunesi, a new Upper Jurassic allosauroid (Dinosauria: Theropoda) from Lourinhã (Portugal). Memórias da Academia de Ciências de Lisboa, 37, 1998, pp. 111-124

- mateus, O. (2005) Dinossauros do Jurássico de Portugal, com destaque para os saurisquios. Tesis doctoral inédita. Universidad de Lisboa, 2005

- MATEUS, O. (2006) Late Jurassic Dinosaurs from the Morrison Formation (USA), The Lourinhã And Alcobaça Formations (Portugal), and the Tendaguru Beds (Tanzania): A comparison. Paleontology and Geology of the Upper Jurassic Morrison Formation. New Mexico Museum of Natural History and Science Bulletin, n. ${ }^{\circ} 36,2006$, pp. 223231

- MATEUS, O.; ANTUNES, M. (2001) Draconyx loureiroi, a new camptosauridae (Dinosauria, Ornithopoda) from the Late Jurassic of Lourinhã, Portugal. Annales de Paléontologie, 87, 2001, pp. 61-73

- MATEUS, O.; WALEN, A.; ANTUNES, M. T. (2006) The large theropod fauna of the Lourinha Formation (Portugal) and its similarity to that of the Morrison Formation, with a description of a new species of Allosaurus. Paleontology and Geology of the Upper Jurassic Morrison Formation. New Mexico Museum of Natural History and Science Bulletin, 36, 2006, pp. 123-129

- MATEUS, O.; MAIDMENT, S. C. R.; CHRISTIANSEN, N. A. (2009) A new long-necked 'sauropod-mimic' stegosaur and the evolution of the plated dinosaurs. Proceedings of the Royal Society B, 276 (1663), 2009, 1815-1821

- MATEUS, O.; MANNION, P. D.; UPCHURCH, P. (2014) Zby atlanticus, a new turiasaurian sauropod (Dinosauria, Eusauropoda) from the Late Jurassic of Portugal. Journal of Vertebrate Paleontology, 34 (3), 2014, pp. 618-634

- McDONALD, A. T. (2011) The taxonomy of species assigned to Camptosaurus (Dinosauria: Ornithopoda). Zootaxa, 2783, 2011, pp. 52-68

- McDONALD, A. T.; ESPÍlEZ, E.; MAMPEL, L.; KIRKLAND, J.I.; ALCALÁ, L. (2012) An unusual new basal iguanodont (Dinosauria: Ornithopoda) from the Lower Cretaceous of Teruel, Spain. Zootaxa, 3595, 2012, pp. 6176

- MOCHO, P. (2016) Evolutionary History of Upper Jurassic Sauropods from the Lusitanian Basin (Portugal). Tesis doctoral inédita, Universidad Autónoma de Madrid, 2016

- MOCHO, P.; ROYO-TORRES, R.; ORTEGA, F. (2014) Phylogenetic reassessment of Lourinhasaurus alenquerensis, a basal Macronaria (Sauropoda) from the Upper Jurassic of Portugal. Zoological Journal of the Linnean Society, 170 (4), pp. 875-916

- MOCHO, P.; ROYO-TORRES, R.; ORTEGA, F. (2017) New data for the Portuguese brachiosaurid Lusotitan atalaiensis (Sobral Formation, Upper Jurassic). Historical Biology, 29 (6), 2017, pp. 789-817

- MOCHO, P.; ROYO-TORRES, R.; PIMENTEL, N.; ESCASO, F.; MALAFAIA, E.; MIGUEL CHAVES, C.; NARVÁEZ, I.; PÉREZ-GARCÍA, A.; SILVA ORTEGA, B. C.; ORTEGA, F. (2017) Stratigraphic distribution of the Upper Jurassic sauropod record in the Lusitanian Basin (Portugal). Palaeontologia Electronica, 20.2.27A, 2017, pp. 1-50

- moratalla, J. J. (1993) Restos indirectos de dinosaurios del registro español: Paleoicnología de la Cuenca de Cameros (Jurásico Superior-Cretácico Inferior) y Paleoología del Cretácico Superior. Tesis doctoral inédita, Universidad Autónoma de Madrid, 1993

- MORATALLA, J. J.; SANZ J. I.; JIMÉNEZ, S (1997) Dinosaurios en La Rioja. Guía de yacimientos paleoicnológicos. Logroño: Iberdrola, Sección de Mineralogía y Paleontología, 1997

- MORATALLA, J. J.; HERNÁN, J.; JIMÉNEZ, S. (2003) Los Cayos dinosaur tracksite: overview on the Lower Cretaceous ichno-diversity of the Cameros Basin (Cornago, La Rioja Province, Spain). Ichnos, 10, pp. 229-240

- MORENO-AZANZA, M. (2014) Los huevos fósiles de amniotas del Cretácico de la Península Ibérica: tafonomía, formación de la cáscara y sistemática. Tesis doctoral inédita. Universidad de Zaragoza, 2014

- ORTEGA, F.; ESCASO, F.; GASULLA, J. M.; DANTAS, P.; SANZ, J. L. (2006) Dinosaurios de la Península Ibérica. Estudios Geológicos, 62, 2006, pp. 219-240

- ORTEGA, F.; SANZ, J. L.; BARROSO-BARCENILLA, 
F.; CAMBRA-MOO, O.; ESCASO, F.; GARCÍA-OLIVA, M.; MARCOS-FERNÁNDEZ, F. (2008) El yacimiento de macrovertebrados fósiles del Cretácico Superior de "Lo Hueco" (Fuentes, Cuenca). Palaeontologica Nova, SEPAZ, 8, 2008, pp. 119-131

- ORTEGA, F.; ESCASO, F.; SANZ, J. L. (2010) A bizarre, humped Carcharodontosauria (Theropoda) from the Lower Cretaceous of Spain. Nature, 467 (7312), 2010, pp. 203206

- PEREDA-SUBERBIOLA, X. (1999) Ankylosaurian dinosaur remains from the Upper Cretaceous of Laño (Iberian Peninsula). Estudios del Museo de Ciencias Naturales de Álava, 14 (1), 1999, pp. 273-288

- PEREDA-SUBERBIOLA, X.; SANZ, J. L. (1999) The ornithopod dinosaur Rhabdodon from the Upper Cretaceous of Laño (Iberian Peninsula). Estudios del Museo de Ciencias Naturales de Álava, 14 (1), 1999, pp. 257-272

- PEREDA-SUBERBIOLA, X.; RUIZ-OMEÑACA, J. I. (2005) Los primeros descubrimientos de dinosaurios en España. Revista Española de Paleontología, 10, 2005, pp. 15-58

- PEREDA-SUBERBIOLA, X.; FUENTES, C.; MEIJIDE, M.; MEIJIDE-FUENTES, F.; MEIJIDE-FUENTES, M. (2007) New remains of the ankylosaurian dinosaur Polacanthus from the Lower Cretaceous of Soria, Spain. Cretaceous Research, 28, 2007, pp. 583-596

- PEREDA-SUBERBIOLA, X.; CANUdO, J. I.; CRUZADOCABALLERO,P.; BARCO, J. L.; LÓPEZ-MARTÍNEZ, N.; OMS, O.; RUIZ-OMEÑACA, J. I. (2009) The last hadrosaurid dinosaurs of Europe: A new lambeosaurine from the Uppermost Cretaceous of Aren (Huesca, Spain). Comptes Rendus Palevol, 8 (6), 2009, pp. 559-572

- PÉREZ-LORENTE, F. (2003) Icnitas de dinosaurios del Cretácico en España. En PÉREZ-LORENTE, F.; ROMERO MOLINA, M. ${ }^{a}$ M.; RIVAS CARRERA, P. (coord.) Dinosaurios y otros reptiles mesozoicos de España. Universidad de La Rioja: Instituto de Estudios Riojanos, 2003, pp. 49-108 (Ciencias de la Tierra; 26)

- PÉREZ-LORENTE, F.; CUENCA, G.; AURELL, M.; CANUDO, J. I.; SORIA, A. R.; RUIZ- OMEÑACA, J. I. (1997) Las Cerradicas tracksite (Berriasian, Galve, Spain): Growing evidence for quadrupedal ornithopods. Ichnos, 5, 1997, pp. $109-120$

- PÉREZ-MORENO, B. P.; SANZ, J. L.; BUSCALIONI, A. D.; MORATALLA, J. J.; ORTEGA, F.; RASKIN-GUTMAN, D. (1994) A unique multitoothed ornithomimosaur from the Lower Cretaceous of Spain. Nature, 30, 1994, pp. 363-367

- PÉREZ PÉREZ, B. (2004) Pelecanimimus polyo don: Anatomia, sistemática y Paleobiología de un Orni thomimosauria (Dinosauria: Theropoda) de Las Hoyas
(Cretácico Inferior; Cuenca, España). Tesis doctoral inédita, Universidad Autónoma de Madrid, 2004

- PIÑUELA, L. (2016) Huellas de dinosaurios y de otros reptiles del Jurásico Superior de Asturias. Tesis doctoral inédita, Universidad de Oviedo, 2016

- PRIETO-MÁRQUEZ, A.; GAETE, R.; RIVAS, G.; GALOBART, Á.; BOADA, M. (2006) Hadrosauroid dinosaurs from the Late Cretaceous of Spain: Pararhabdodon isonensis revisited and Koutalisaurus kohlerorum, gen. et sp. nov. Journal of Vertebrate Paleontology, 26 (4), 2006, pp. 929-943

- POZA, B.; SUÑER, M.; SANTOS-CUBEDO, A.; GALOBART, A. (2008) Los dinosaurios de Cataluña y Valencia: 20 años de investigación por divulgar. Un proyecto de divulgación de la paleontología. Paleontologica Nova, SEPAZ, 8, 2006, pp. 369-380

- RAUHUT, O. W. M. (2003) A tyrannosaurid dinosaur from the Upper Jurassic of Portugal. Palaeontology, 46 (5), 2003, pp. 903-910

- RAZZOLINI, R. (2016) Morphological variation and ichnotaxonomy of dinosaur tracks. Linking footprint shapes to substrate and trackmaker's anatomy and locomotion. Tesis doctoral inédita, Universitat Autònoma de Barcelona, 2016

- ROYO-TORRES, R. (2006) Sistemática y Paleobiología del saurópodo (Dinosauria) del Aptiense inferior de Peñarroya de Tastavins (Teruel, España). Tesis doctoral inédita, Universidad de Zaragoza

- ROYO-TORRES, R. (2009a) El saurópodo de Peñarroya de Tastavins. Teruel: Instituto de Estudios TurolensesFundación Conjunto Paleontológico de Teruel-Dinópolis, 2009

- ROYO-TORRES, R. (2009b) Los dinosaurios saurópodos en la Península Ibérica. En Actas de las IV Jornadas Internacionales sobre Paleontología de dinosaurios y su entorno. Salas de los Infantes (Burgos, España). Burgos: Colectivo Arqueológico-Paleontológico de Salas, 2009, pp. 139-166

- ROYO-TORRES, R. COBOS, A.; ALCALÁ, L. (2006) A Giant European Dinosaur and a New Sauropod Clade. Science, 314, 2006, pp. 1925-1927

- ROYO-TORRES, R.; COBOS, A.; ABERASTURI, A.; ESPÍLEZ, E.; FIERRO, I.; GONZÁLEZ, A.; LUQUE, L.; MAMPEL, L.; ALCALÁ, L. (2009) High european sauropod dinosaur diversity during Jurassic-Cretaceous transition in Riodeva (Teruel, Spain). Palaeontology, 52 (5), 2009, pp. 1009-1027

- ROYO-TORRES, R.; ALCALÁ, L.; COBOS, A. (2012) A new specimen of the Cretaceous sauropod Tastavinsaurus sanzi from El Castellar (Teruel, Spain), and a phylogenetic 
analysis of the Laurasiformes. Cretaceous Research, 34 2012, pp. 61-83

- ROYO-TORRES, R.; UPCHURCH, P.; MANNION, P.; MAS, R. COBOS, A.; GASCÓ, F.; ALCALÁ, L. SANZ, J. L. (2014) The anatomy, phylogenetic relationships and stratigraphic position of the Tithonian-Berriasian Spanish sauropod dinosaur Aragosaurus ischiaticus. Zoological Journal of the Linnean Society, vol. 171 (3), 2014, pp. 623655

- ROYO-TORRES, R.; UPCHURCH, P.; KIRKLAND, J. I.; DEBLIEUX, D. D.; FOSTER, J. R.; COBOS, A.; ALCALÁ, L. (2017) Descendants of the Jurassic turiasaurs from Iberia found refuge in the Early Cretaceous of western USA. Scientific Reports, 7, 14311, 2017, pp. 1-12

- ROYO-TORRES, R.; FUENTES, C.; MEIJIDE, M.; MEIJIDE-FUENTES, F.; MEIJIDE-FUENTES, M. (2017) A new Brachiosauridae sauropod dinosaur from the Lower Cretaceous of Europe (Soria province, Spain). Cretaceous Research, 80, 2017, pp. 38-55

- RUIZ-OMEÑACA, J. I. (2006) Restos directos de dinosaurios (Saurischia, Ornithischia) en el Barremiense (Cretácico Inferior) de la Cordillera Ibérica en Aragón (Teruel, España). Tesis doctoral inédita, Universidad de Zaragoza, 2006

- RUIZ-OMEÑACA, J. I. (2011) Delapparentia turolensis nov. gen et sp., un nuevo dinosaurio iguanodontoideo (Ornithischia: Ornithopoda) en el Cretácico Inferior de Galve. Estudios Geológicos, 67 (1), 2011, pp. 83-110

- RUIZ-OMEÑACA, J. I.; CANUDO, J. I.; CUENCABESCÓS, G.; CRUZADO-CABALLERO, P. L.; GASCA, J. M.; MORENO-AZANZA, M. (2012) A new basal ornithopod dinosaur from the Barremian of Galve, Spain. Comptes Rendus Palevol,11 (6), 2012, pp. 435-444

- SÁNCHEZ-HERNÁNDEZ, B.; BENTON M. J. (2014) Filling the ceratosaur gap: A new ceratosaurian theropod from the Early Cretaceous of Spain. Acta Palaeontologica Polonica, 59 (3), 2014, pp. 581-600

- SANTOS, V. (2003) Pistas de dinossáurio no JurássicoCretácico de Portugal. Considerações paleobiológicas e paleoecológicas. Tesis doctoral inédita, Universidad Autónoma de Madrid, 2003

- SANTOS, V. F.; MORATALLA J. J.; ROYO-TORRES, R. (2009) New sauropod trackways from the Middle Jurassic of Portugal. Acta Paleontologica Polonica, 54 (3), 2009, pp. 409-422

- SANTOS, V. F.; COBOS, A.; ALCALÁ, L. (2011) Pedreira do Galinha. En BRILHA, J.; PEREIRA, P. (ed.) Património geológico: geossítios a visitar em Portugal/Geological heritage: geosites to visit in Portugal. Porto: Porto Editora, 2011, pp. 60-61
- SANZ, J. L.; BUSCALIONI, A. D.; CASANOVAS, M. L. SANTAFÉ, J. V. (1987) Dinosaurios del Cretácico Inferior de Galve (Teruel, España). Estudios Geológicos, vol. extr. Galve-Tremp, 1987, pp. 45-64

- SANZ, J. L.; BONAPARTE, J. F.; LACASA, A. (1988) Unusual Early Cretaceous birds from Spain. Nature, 331, 1988, pp. 433-435

- SANZ, J. L.; BONAPARTE, J. F. (1992) A New Order of Birds (Class Aves) from the Lower Cretaceous of Spain. En BECKER, J. J. (ed.) Papers in avian paleontology honoring Pierce Brodkorb. Los Angeles: Natural History Museum of Los Angeles County, 1992, pp. 38-49 (Science Series; 36)

- SANZ, J. L.; BUSCALIONI, A. D. (1992) A new bird from the Early Cretaceous of Las Hoyas, Spain, and the early radiation of birds. Palaeontology, 35 (4), 1992, pp. 829-845

- SANZ, J. L.; CHIAPPE, L. M.; PÉREZ-MORENO, B. P.; BUSCALIONI, Á. D.; MORATALLA, J. J.; ORTEGA, F.; POYATO-ARIZA, F. J. (1996) An Early Cretaceous bird from Spain and its implications for the evolution of avian flight. Nature, 382 (6590), 1996, pp. 442-445

- SANZ, J. L.; POWELL, J. E.; LE LOEUFF, J.; MARTÍNEZ, R.; PEREDA-SUBERBIOLA, X. (1999) Sauropod remains from the Upper Cretaceous of Laño (north central Spain). Titanosaur phylogenetic relationships. Estudios del Museo de Ciencias Naturales de Álava, n. ${ }^{\circ} 14$ (1), 1999, pp. 235255

- SAUVAGE, H.-É. (1897-98) Vértebrés fossiles du Portugal. Contribution á l'étude des poissons et des reptiles du Jurassique et du Crétacé. Mémoires de la Direction des Travaux Géologiques du Portugal

- SCHULP, A.; BROKX, W. A. (1999) Maastrichtian sauropod footprints from the Fumanya site, Bergueda Spain. Ichnos, 6, 4, 1999, pp. 239-250

- SUÑER, M. (2016) Estudio paleontológico de los dinosaurios saurópodos del tránsito Jurásico-Cretácico (Titoniense-Berriasiense) de la Formación Villar del Arzo bispo en el término municipal de Alpuente (comarca de Los Serranos, Valencia, España). Tesis doctoral inédita, Universidad Autónoma de Madrid, 2016

- TORCIDA FERNÁNDEZ-BALDOR, F. (ed.) (2006) Actas del Simposio Internacional Huellas que perduran. Icnitas de dinosaurios: patrimonio y recurso. Valladolid: Fundación del Patrimonio Histórico de Castilla y León, 2006

- TORCIDA FERNÁNDEZ-BALDOR, F. (2012) Siste mática, Filogenia y Análisis Paleobiogeográfico de Deman dasaurus darwini (Sauropoda, Rebbachisauridae) del Barremiense Superior-Aptiense de Burgos (España). Tesis doctoral inédita, Universidad de Zaragoza, 2012

- TORCIDA FERNÁNDEZ-BALDOR, F.; CANUDO, J .I.; HUERTA, P.; MONTERO, D.; PEREDA-SUBERBIOLA, 
X.; SALGADO, L. (2011) Demandasaurus darwini, a new rebbachisaurid sauropod from the Early Cretaceous of the Iberian Peninsula. Acta Palaeontologica Polonica, 56 (3), 2011, pp. 535-552

- TORCIDA FERNÁNDEZ-BALDOR, F.; CANUDO, J. I.; HUERTA, P.; MORENO-AZANZA, M.; MONTERO, D. (2017) Europatitan eastwoodi, a new sauropod from the lower Cretaceous of Iberia in the initial radiation of somphospondylans in Laurasia. PeerJ, 5, 2017, pp. e3409

- TORICES-HERNÁNDEZ, A. (2007) Los dinosaurios terópodos del Cretácico Superior de la Cuenca Surpirenaica. Tesis doctoral inédita, Universidad Complutense de Madrid, 2007

- VERDú, F. J. (2017) Sistemática, filogenia y paleobiología de Iguanodon galvensis (Ornithopoda, Dinosauria) del Barremiense inferior (Cretácico Inferior) de Teruel (España). Tesis doctoral inédita, Universidad de Valencia, 2017

- VERDÚ, F. J.; ROYO-TORRES, R.; COBOS, A.; ALCALÁ. L. (2015) Perinates of a new species of Iguanodon (Ornithischia: Ornithopoda) from the lower Barremian of Galve (Teruel, Spain). Cretaceous Research, 56, 2015, pp. 250-264

- VERDÚ, F. J.; ROYO-TORRES, R.; COBOS, A.; ALCALÁ L. (2017) New systematic and phylogenetic data about the early Barremian Iguanodon galvensis (Ornithopoda: Iguanodontoidea) from Spain. Historical Biology, 30:4, 437474, DOI: 10.1080/08912963.2017.1287179

- VERDÚ, F. J.; GODEFROIT, P.; ROYO-TORRES, R.; COBOS, A.; ALCALÁ, L. (2017) Individual variation in the postcranial skeleton of Iguanodon bernissartensis (Dinosauria: Ornithopoda). Cretaceous Research, 74, 2017, pp. 65-86

- VILA, B. (2010) Los saurópodos del Cretácico superior del sur de Europa: diversidad, icnología y biología reproductiva. Tesis doctoral inédita, Universidad Autónoma de Madrid, 2010

- VILA, B.; OMS, O.; GALOBART, A. (2005) Manusonly titanosaurid trackway from Fumanya (Maastrichtian, Pyrenees): further evidence for an underprint origin. Lethaia, 38, 2005, pp. 211-218

- VILA, B.; RIERA, V.; BRAVO, A. M.; OMS, O.; VICENS, E.; ESTRADA, R.; GALOBART, À. (2011) The chronology of dinosaur oospecies in southern Europe: refinements from the Maastrichtian succession of the Eastern Pyrenees. Cretaceous Research, 32, 2011, pp. 378-386 